\title{
Simulation of the Recharge Area for Frederick Springs, Dane County, Wisconsin
}

Water-Resources Investigations Report 00-4172

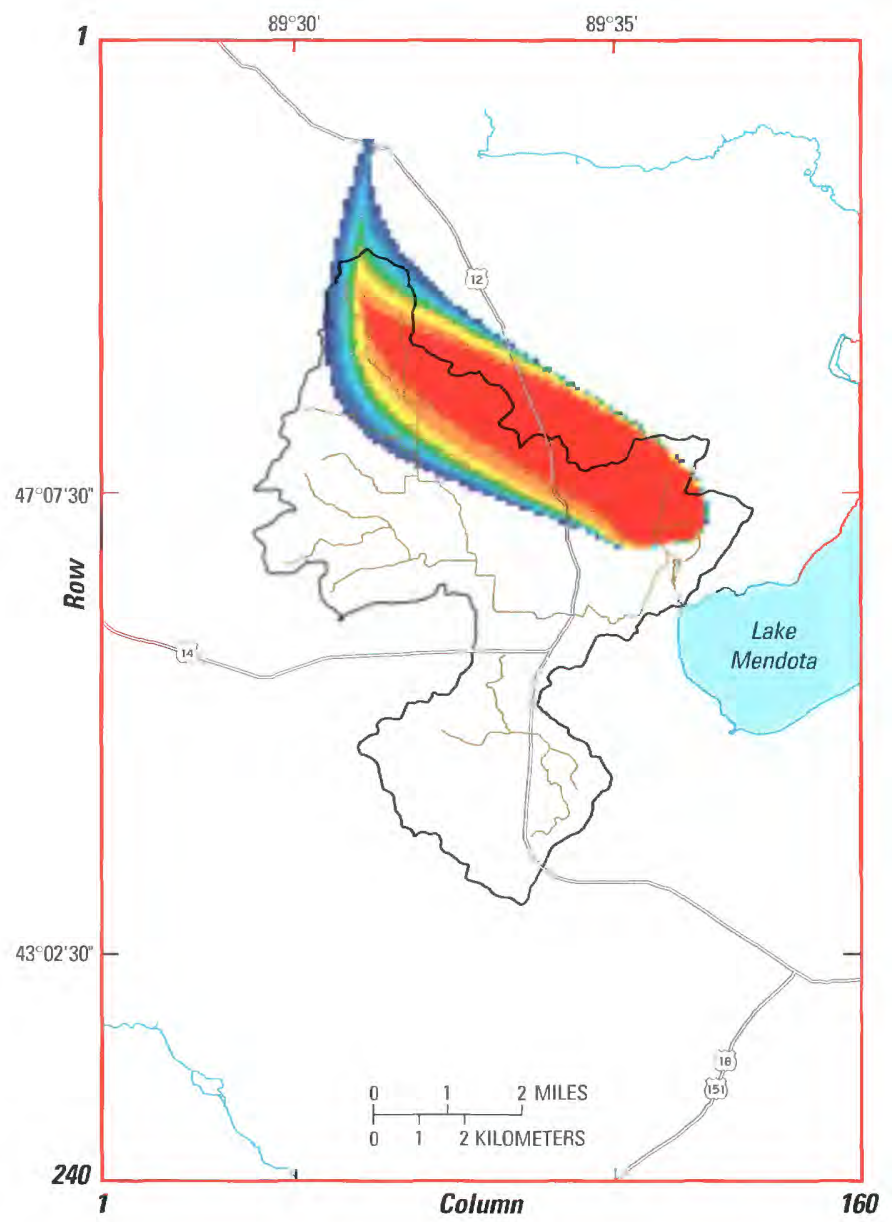

EXPLANATION

Pheasant Branch stream network

Other stream

$\tau$ Surface-water divide

00

Probability

of capture

Prepared in cooperation with the

City of Middleton

Wisconsin Department of Natural Resources

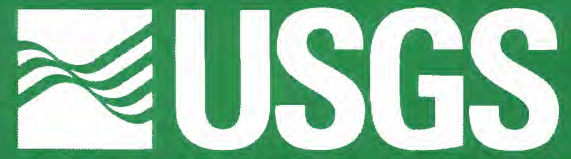





\section{Simulation of the Recharge Area for Frederick Springs, Dane County, Wisconsin}

\section{By R.J. Hunt and J.J. Steuer}

U.S. GEOLOGICAL SURVEY

Water-Resources Investigations Report 00-4172

Prepared in cooperation with the

City of Middleton

Wisconsin Department of Natural Resources

Middleton, Wisconsin

2000

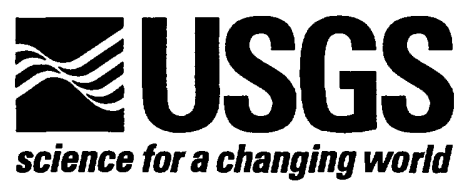




\title{
U.S. DEPARTMENT OF THE INTERIOR BRUCE BABBITT, Secretary
}

\author{
U.S. GEOLOGICAL SURVEY \\ Charles G. Groat, Director
}

Any use of trade, product, or firm names is for descriptive purposes only and does not imply endorsement by the U.S. Government.

For additional information write to:

Copies of this report can be purchased from:

District Chief

U.S. Geological Survey

8505 Research Way

Middleton, WI 53562-3586
U.S. Geological Survey

Branch of Information Services

Box 25286

Denver, CO 80225-0286 


\section{CONTENTS}

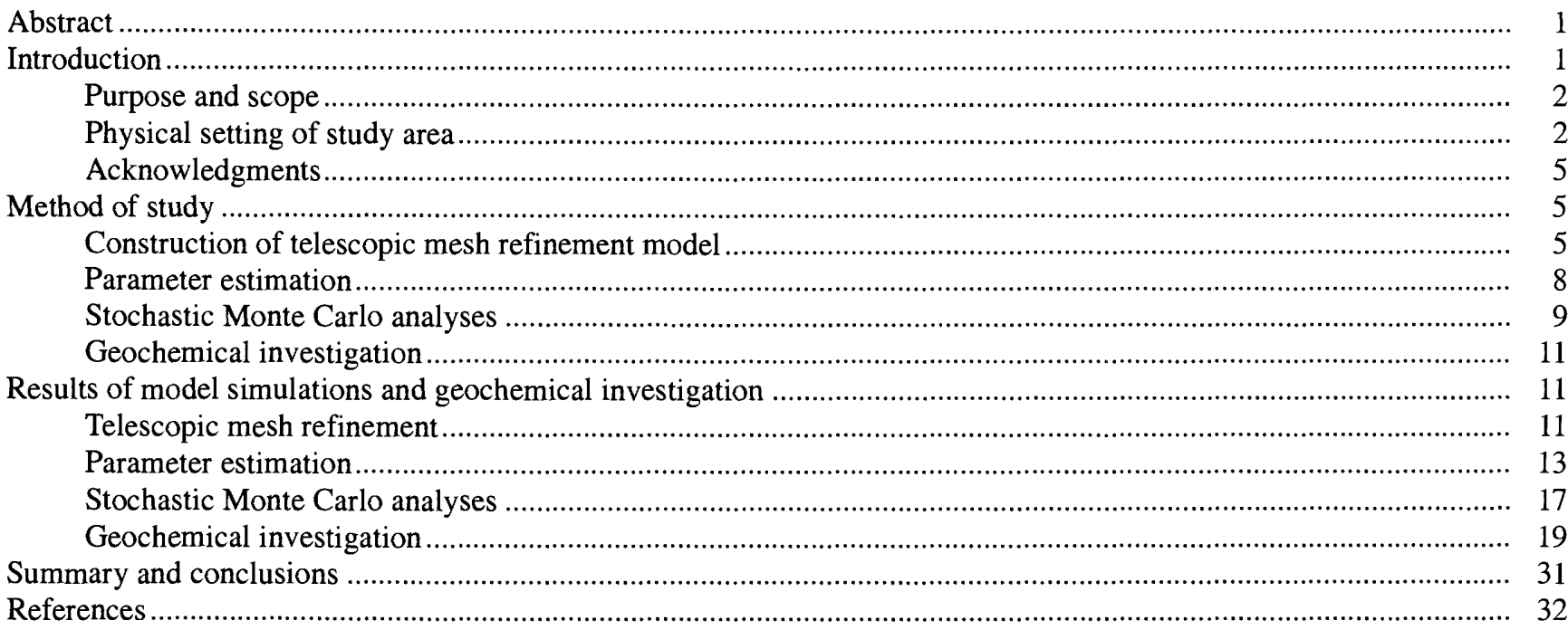

\section{FIGURES}

1-3. Maps showing:

1. Relation of the telescopic mesh refinement model to the Dane County Regional Model ............................... 3

2. Surface water features and high capacity wells used in the telescopic mesh refinement model....................... 4

3. Locations of hydrologic response units used in the Pheasant Branch surface water modeling ........................ 7

4. Plot of parameter sensitivity from the UCODE parameter estimation ............................................................ 10

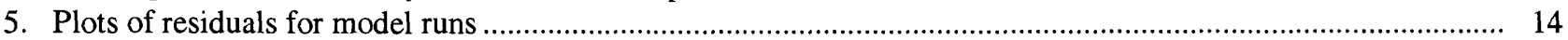

6. Map showing area where the connection between layers 2 and 3 was modified in the telescopic mesh

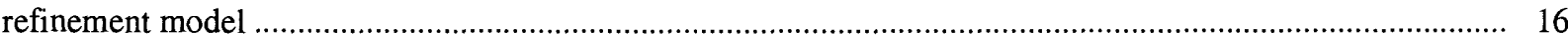

7-9. Results of stochastic MODFLOW runs showing:

7. Mean absolute error for 200 realizations......................................................................................... 18

8. Conditioned stochastic MODFLOW runs for the upper bedrock aquifer and the lower bedrock aquifer ......... 20

9. Conditioned stochastic MODPATH runs for the upper bedrock aquifer and the lower bedrock aquifer........... 22

10. Map showing location of the Springs and geochemical sampling sites ........................................................... 25

11-15. Graphs showing:

11. Average specific conductance measurements and standard deviations for $1998-99$................................. 26

12. Average calcium concentrations and standard deviations for 1998-99 .................................................... 26

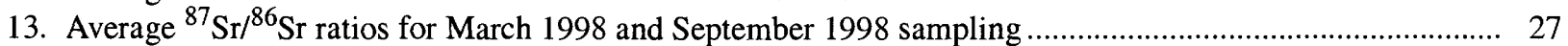

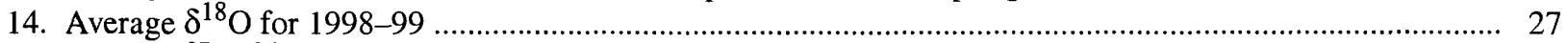

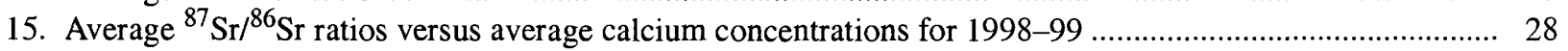

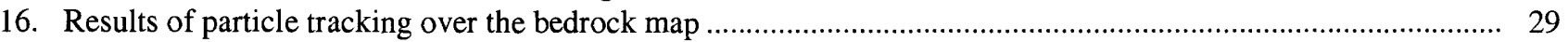

17-19. Graphs showing:

17. Average nitrate + nitrite concentrations and standard deviations for $1998-99$......................................... 30

18. Average nitrate + nitrite concentrations versus average chloride concentrations for the Frederick Spring sampling, 1998-99

19. Average total filterable phosphorus concentrations and standard deviations for $1998-99$.......................... 31

\section{TABLES}

1. Parameters used in the Dane County Regional Model and telescopic mesh refinement model

2. Results of the Pheasant Branch UCODE runs using the telescopic mesh refinement model and the

Dane County Regional Model

3. Results of geochemical sampling, 1998-99 


\begin{tabular}{|c|c|c|}
\hline Multiply & By & To Obtain \\
\hline \multicolumn{3}{|c|}{ Length } \\
\hline $\begin{array}{r}\text { inch (in.) } \\
\text { foot (ft) } \\
\text { mile (mi) }\end{array}$ & $\begin{array}{l}25.4 \\
0.3048 \\
1.609\end{array}$ & $\begin{array}{l}\text { millimeter } \\
\text { meter } \\
\text { kilometer }\end{array}$ \\
\hline \multicolumn{3}{|c|}{ Area } \\
\hline $\begin{array}{r}\text { acre }(\mathrm{A}) \\
\text { square foot }\left(\mathrm{ft}^{2}\right) \\
\text { square mile }\left(\mathrm{mi}^{2}\right)\end{array}$ & $\begin{array}{l}0.4047 \\
0.09290 \\
2.590\end{array}$ & $\begin{array}{l}\text { hectare } \\
\text { square meter } \\
\text { square kilometer }\end{array}$ \\
\hline \multicolumn{3}{|c|}{ Volume } \\
\hline cubic foot $\left(\mathrm{ft}^{3}\right)$ & 7.4805 & gallon \\
\hline \multicolumn{3}{|c|}{ Hydraulic conductivity* } \\
\hline foot per day (ft/d) & 0.3048 & meter per day \\
\hline
\end{tabular}

Sea level: In this report, "sea level" refers to the National Geodetic Vertical Datum of 1929 (NGVD of 1929)—a geodetic datum derived from a general adjustment of the first-order level nets of both the United States and Canada, formerly called Sea Level Datum of 1929.

*Hydraulic conductivity: The standard unit for hydraulic conductivity is cubic foot per day per square foot of aquifer cross-sectional area $\left(\mathrm{ft}^{3} / \mathrm{d}\right) / \mathrm{ft}^{2}$. In this report, the mathematically reduced form, feet per day $(\mathrm{ft} / \mathrm{d})$, is used for convenience.

\section{Other abbreviations:}

$\mathrm{ft}^{3} / \mathrm{s} \quad$ cubic feet per second

in/yr inches per year

$\mathrm{ft} / \mathrm{d} \quad$ feet per day

$\mathrm{K}_{\mathrm{h}} \quad$ horizontal hydraulic conductivity

$\mathrm{K}_{\mathrm{v}} \quad$ vertical hydraulic conductivity

The stratigraphic nomenclature used in this report is that of the Wisconsin Geological and Natural History Survey and does not necessarily follow usage of the U.S. Geological Survey. 


\title{
Simulation of the Recharge Area for Frederick Springs, Dane County, Wisconsin
}

\author{
By R.J. Hunt and J.J. Steuer
}

\section{Abstract}

The Pheasant Branch watershed in Dane County is expected to undergo development. There are concerns that this development will adversely affect water resources, including Frederick Springs, a large spring complex in the watershed. The spring's recharge area was delineated using a telescopic mesh refinement (TMR) model constructed from an existing regional-scale groundwater flow model, and further refined by adding nearby surface-water features, a refined recharge array based on a surface-water model, and increasing the vertical leakage between the deep aquifers. This TMR model was formally optimized using the parameter estimation code UCODE. The results of optimization demonstrated that the best fit to measured heads and fluxes was obtained by using a horizontal hydraulic conductivity two times that of the original regional model for layer 2 and 80 percent smaller for layer 3 . This range of parameter values was formally considered using a stochastic Monte Carlo approach.

Two-hundred model runs used uniformly distributed, randomly sampled, horizontal hydraulic conductivity values within the range given by the TMR optimized values and the previously constructed regional model. A probability distribution of particles captured by the spring, or a "probabilistic capture zone" was calculated from the realistic Monte Carlo results (136 runs of 200). In addition to portions of the local surface watershed, the capture zone encompassed distant areas in the North Fork of the Pheasant Branch watershed and areas entirely outside of the Pheasant Branch-demonstrating that the ground-watershed and surface watershed do not coincide.

Analysis of samples from the springs and a nearby municipal well identified large contrasts in chemistry, even for springs within 50 feet of one another. The differences were stable over time, were present in both ion and isotope analyses, and showed a distinct gradation from high nitrate, high calcium, Ordovician-carbonate dominated water in western spring vents to low nitrate, lower calcium, Cambrian-sandstone influenced water in eastern spring vents. The difference in chemistry was attributed to distinctive bedrock geology as demonstrated by overlaying the 50 percent probability capture zone over a bedrock geology map for the area. This finding gives additional confidence to the capture zone calculated by the ground-water flow model.

\section{INTRODUCTION}

As the City of Middleton and its surroundings continue to develop, the Pheasant Branch watershed is expected to undergo significant urbanization. The watershed encompasses mixed land uses and includes Frederick Springs, a large spring complex near the downstream end of the basin. For the downstream city of Middleton, headwater urbanization can mean increased flood peaks, increased water volume and increased pollutant loads. More subtly, the effects of urbanization also may reduce ground-water recharge and adversely affect down-gradient ecosystems such as Pheasant Branch marsh. The effects of stormwater runoff and wetland loss on reduced ground-water recharge are complex because the surface-water system is coupled to the underlying ground-water system as in most parts of Wisconsin. In many cases, the movement of water from one system to the other varies seasonally or daily, depending on transient events. Therefore, it is difficult to reliably predict the effects of urbanization on stream baseflow and spring flows a priori. Moreover, mitigating any adverse effects after development has taken place can be expensive and administratively difficult. Overlying these concerns are issues such as land owners' rights - both of those developing their land and those whose land is affected by this development-the rights of the public, and stewardship of the resource. With these often-contradictory goals, a scientific basis for assessing effects and effectiveness of mitigation measures is important for effective decision making. This scientific basis was the goal of a study completed 
by the U.S. Geological Survey in cooperation with the City of Middleton and the Wisconsin Department of Natural Resources.

Others have investigated portions of the Pheasant Branch watershed. Previous work either was included in a larger regional study or focused solely on the stream itself. Krohelski and others (2000) included the basin in their larger ground-water flow model for Dane County; however, the system was coarsely gridded and did not include many of the hydrologic features that are locally important (such as Frederick Spring, Dorn Creek). Grant and Goddard (1980) investigated channel erosion and sediment transport in the stream. Krug and Goddard (1986) evaluated the effects of urbanization on the stream system. Selbig (1996) characterized the Pheasant Branch Marsh and springs as part of a UW-Madison wetlands ecology course. A companion volume to this report describing the surface-water modeling work and effects of predicted stresses on the hydrologic systems of the Pheasant Branch watershed is in preparation.

While many hydrologic studies focus only on one component of the ground water-surface water continuum, the overall project includes all elements of the hydrologic cycle including rainfall, snowmelt, evapotranspiration, interflow, streamflow, baseflow, and ground-water flow. The entire hydrologic system is characterized quantitatively; output from surface-water modeling (recharge) is coupled to the ground-water model input. This allows more realistic scenarios (that is, urbanization affects surface-water storm flows and ground-water recharge) and allows an additional check for reasonableness. While both surface-water and ground-water modeling are being performed as part of the overall project, this report will focus on the groundwater modeling aspects and assessment of recharge rates derived from the surface-water model.

\section{Purpose and Scope}

The purpose of the overall study was to provide a scientific basis for evaluating changes to the water resources of the Pheasant Branch watershed as the hydrologic system responds to changes in land use. Of special interest is the Frederick Springs system because it is an important water resource in the Pheasant Branch watershed and an essential source of water for a rare wild rice community in the Pheasant Branch Marsh. Identifying the source waters for the spring is the first step in ensuring its protection. The purpose of this report is to describe ground-water flow modeling and geochemical information used to identify the source of water that sustains the spring complex.

\section{Physical Setting of Study Area}

The Pheasant Branch watershed (fig. 1) consists of $24 \mathrm{mi}^{2}$ located on the edge of the Driftless Area in Dane County. The geology of the Pheasant Branch area was derived from the hydrogeologic framework (Bradbury and others, 1999) and existing regional model of the area (Krohelski and others, 2000) and, from base upward, consists of:

(1) an impermeable Precambrian basement,

(2) an extensive lower bedrock aquifer that consists of a Cambrian sandstone aquifer (Mt. Simon and Eau Claire sandstone) that ranges between 400 and $700 \mathrm{ft}$ and averages $525 \mathrm{ft}$ thick in the Pheasant Branch area,

(3) a shaly confining unit (the Eau Claire Shale) that is absent near Lake Mendota but is as thick as $40 \mathrm{ft}$; the average unit thickness in the Pheasant Branch area is $20 \mathrm{ft}$,

(4) a upper bedrock aquifer consisting primarily of Cambrian sandstones and Ordovician carbonates that are absent under Lake Mendota but can be as thick as $625 \mathrm{ft}$ in western Dane County; the average thickness is $320 \mathrm{ft}$ in the Pheasant Branch area, and

(5) a thin overlying unconsolidated sedimentary unit that is Quaternary in age.

The shale confining unit is present in the western portions of the county, but is absent under the Yahara lakes and in areas in eastern Dane County. The water table is commonly found in the Upper Paleozoic bedrock layer in the Pheasant Branch area; high capacity wells often have boreholes that are open to both the lower bedrock aquifer and the upper bedrock aquifer.

The watershed is composed of a south fork, a north fork and a lower system that flows into the Pheasant Branch Marsh (fig. 2). The south fork is ephemeral and is not included in the ground-water model. At the marsh, flow from Pheasant Branch Creek combines with flows from the spring complex (Springs) and other ground water discharged to the marsh (to the stream channel as well as other springs and minor tributaries); this combined flow ultimately discharges into Lake Mendota. During present conditions, these three components (stream flow, spring flow, and ground-water 


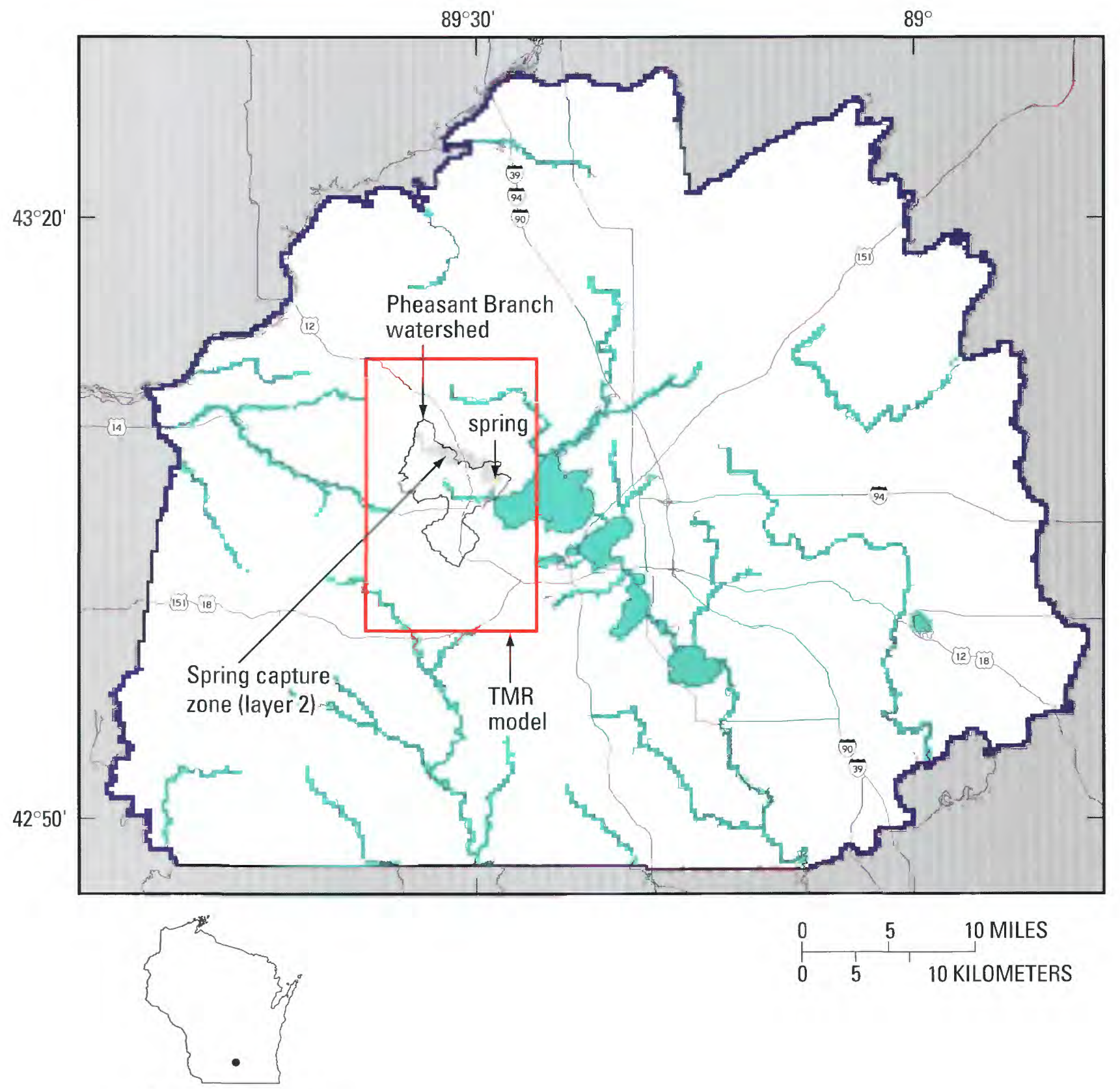

Location of study area in Wisconsin

Figure 1. Relation of the telescopic mesh refinement (TMR) model to the Dane County Regional Model (DCRM). (Grid is used to specify perimeter boundaries for the inset TMR model. Because the spring is a regional feature, the DCRM was also used to coarsely define the capture zone of the spring (shown near the middle of the TMR model) and to test the efficacy of possible changes for the TMR model. Hydrologic features used in the DCRM and the location of the Pheasant Branch watershed are also shown.) 


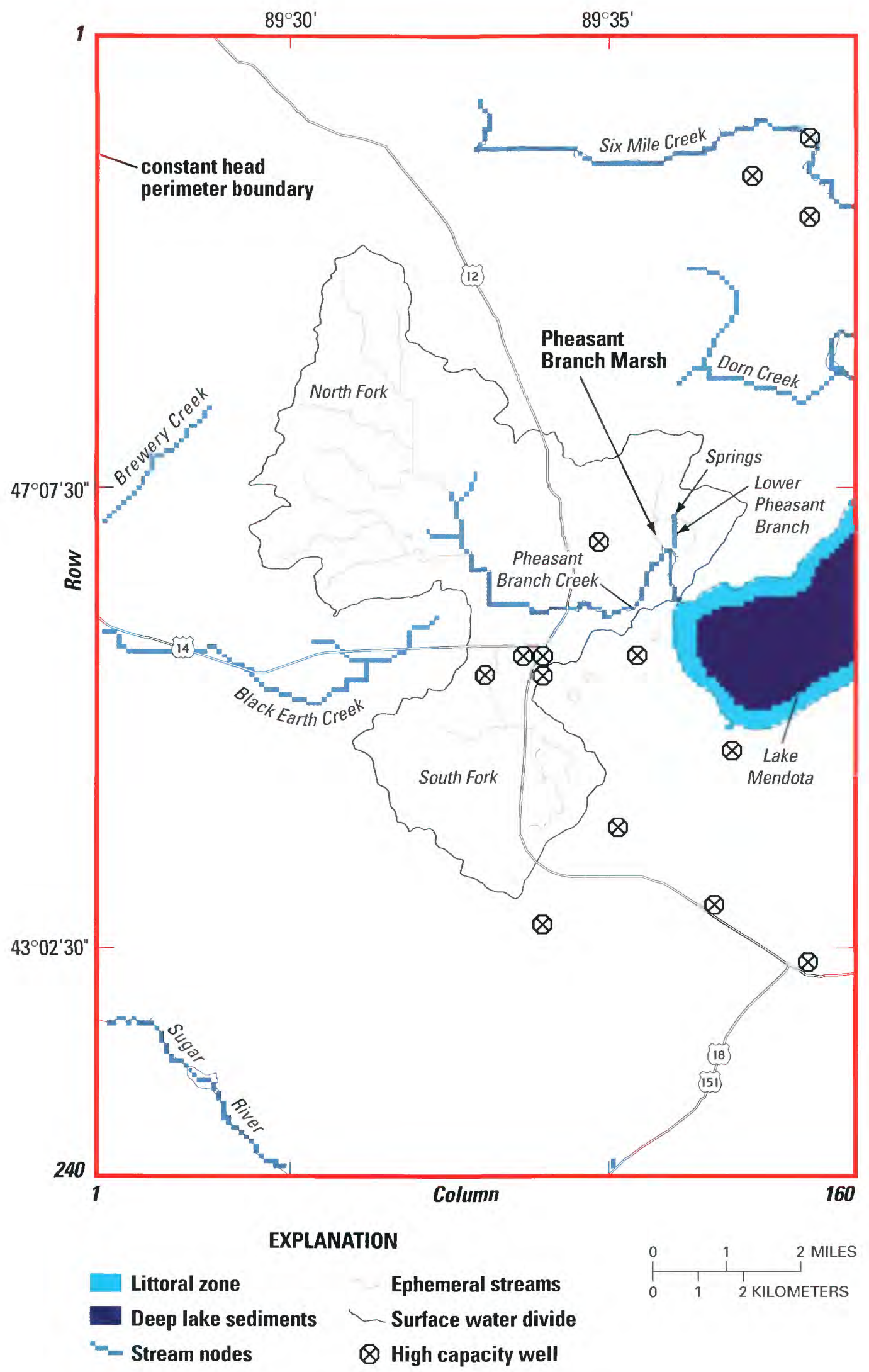

Figure 2. Surface water features and high capacity wells used in the TMR model. (Note smaller grid allows more accurate representation of surface water feature geometry and extent (for example, Pheasant Branch Creek). Surface water features important for the Pheasant Branch watershed are added to those of the DCRM (for example, Brewery Creek, Dorn Creek)). 
discharge to the marsh) are roughly equal (around $2 \mathrm{ft}^{3} / \mathrm{s}$ each) during baseflow conditions (Selbig, 1996).

The drainage network of the watershed has been significantly modified over the last 150 years. Prior to the mid-1880's, the Pheasant Branch watershed upstream of Highway 12 drained into a large wetland that occupied flat-lying land that surrounds the present confluence of the North and South Forks (Maher, 1999). The watershed was closed in most years, but in extremely wet years may have spilled into the Black Earth Creek watershed to the west. In the mid-1880's the wetland was drained to Lake Mendota. Most of the present-day channels in the Pheasant Branch watershed formed after land in the watershed was converted to agricultural uses. The channel that extends from Highway 12 to the Pheasant Branch Marsh has a high gradient ( $90 \mathrm{ft}$ drop over $2 \mathrm{mi}$ ) resulting in high rates of erosion that threaten bridges and sewer lines. The City of Middleton has spent approximately $\$ 500,000$ in the last 30 years in an attempt to protect these structures from erosion.

The Pheasant Branch Marsh is a diverse wetland system that contains stands of native herbaceous and shrub-scrub vegetation near the Springs, reed canary grass and stinging nettles near the Pheasant Branch outlet, and wild rice and cattails near the confluence of the Spring and Pheasant Branch Creek channel (Selbig, 1996). Originally the Pheasant Branch channel flowed north into the Pheasant Branch Marsh and discharged to the northwest part of the wetland, but during the 1950's the channel changed course and followed the southern boundary of the marsh (Grant and Goddard, 1980) as a result of dumping near the old outlet (D’Onofrio, 1973). By 1971, the stream was re-routed to the northwest outlet by the City of Middleton in an attempt to trap sediments and reduce the overall stream gradient. However, the stream system still conveys large amounts of sediment and associated phosphorus to the Lake Mendota system. For example, the Pheasant Branch system had the highest sediment load per unit area for all rural streams measured in Dane County (Lathrop and Johnson, 1979). Increased stormwater flows, a consequence of future development, are expected to exacerbate erosion in the stream channel and sediment transport; these issues have become a topic of concern for the citizens of Middleton (North Fork Pheasant Branch Watershed Committee, 1999).

The lower Pheasant Branch connecting the Pheasant Branch Springs to Lake Mendota is distinct from the rest of the system in a number of ways. First, a channel connects the large spring complex to Pheasant Branch Creek and has probably existed in this location for thousands of years. Secondly, the stream in this area has a flat gradient. Finally, whereas the rest of the stream is characterized by relative low ground-water discharge and high stormwater flows, the springs and associated channel have relatively high ground-water discharge components.

\section{Acknowledgments}

Special thanks are extended to Teresa Mansor for her assistance in collecting and analyzing chemical data. Daniel Feinstein and James Krohelski assisted with regional model simulations. Tom Bullen is thanked for providing strontium isotope analyses. The City of Middleton Public Works Department and the Friends of Pheasant Branch are acknowledged for their assistance throughout the project.

\section{METHOD OF STUDY}

\section{Construction of Telescopic Mesh Refinement Model}

The model approach consists of modifying an inset model extracted from a recently developed MODFLOW (McDonald and Harbaugh, 1988) model (fig. 1) for Dane County (Krohelski and others, 2000), hereafter called the Dane County Regional Model (DCRM). The DCRM grid was used to assign constant head boundary conditions along the perimeter of the inset model (fig. 2) and the inset model grid was refined using a telescopic mesh refinement (TMR) approach following the methodology of Ward and others (1987). The TMR routine was performed using Groundwater Vistas (Rumbaugh and Rumbaugh, 1996). The original grid spacing was $1,312.4 \mathrm{ft}$ on a side; the refined grid is one-fourth the spacing, or $328.1 \mathrm{ft}$ on a side. Thus, every DCRM model node is represented by 16 nodes in the TMR model. As a result of the smaller grid spacing, surface-water features and the hydraulic head distribution were represented more accurately in the TMR model. Therefore, stream-aquifer interactions and three-dimensional effects near the streams were simulated more accurately. A second refinement was the conversion of all streams in the TMR model domain from the MODFLOW River Package (McDonald and Harbaugh, 1988) to the more sophisticated Stream Routing Package (Prudic, 1989). The latter allows accounting of streamflow in the streams, and limits the amount of water a stream 
Table 1. Parameters used in Dane County Regional Model (DCRM) and telescopic mesh refinement (TMR) model

\begin{tabular}{lcccc}
\hline \multicolumn{5}{c}{ Horizontal Hydraulic Conductivity (feet/day) } \\
Layer 1 1 & & & \\
& & TMR base & Head optimized & Head and flux optimized \\
& zone 1 & 0.3 & 0.3 & 0.3 \\
& zone 2 & 0.5 & 0.5 & 0.5 \\
& zone 3 & 1 & 1 & 1 \\
& zone 4 & 3 & 3 & 3 \\
& zone 5 & 5 & 5 & 7 \\
& zone 6 & 7 & 7 & 9.6 \\
Layer 2 & & 5 & 15.0 & 2.0 \\
Layer 3 & & 10 & 0.7 &
\end{tabular}

Nodal Recharge Rate (inches/year)

$\begin{array}{rrr}\text { Original DCRM } & \text { maximum } & 12.4 \\ & \text { minimum } & 0.0 \\ & \text { area weighted average } & 4.8 \\ & & \\ \text { TMR model } & \text { maximum } & 9.5 \\ & \text { minimum } & 2.2 \\ & \text { area weighted average } & 8.0\end{array}$

Leakage Underneath the Springs MODFLOW VCONT (1/day)

Original DCRM for Pheasant Branch Springs

DCRM node representing larger springs area $\quad 0.00001817$

TMR node directly below Springs $\quad 0.00001817$

TMR model in Pheasant Branch Springs

DCRM node representing larger springs area $\quad 0.00446$

TMR node directly below Springs $\quad 0.14$

can lose to the aquifer to the amount of water captured upstream. The simpler River Package was used to simulate Lake Mendota, however, as neither stream routing nor the ability to control infiltration quantities were required for this feature. The final modification to the DCRM model construction was the refinement of the representation of the existing streams and the addition of surface-water features not previously modeled (such as the Springs and Dorn Creek northeast of the Springs -fig. 2) that were not critical for the regional model calibration but were important for the TMR model calibration. The additional surface-water features were simulated using the Stream Routing Package. Added stream nodes used an assumed stream bottom elevation equal to the $5 \mathrm{ft}$ below stream stage and a sediment thickness equal to $1 \mathrm{ft}$. Stream width was set equal to $5 \mathrm{ft}$ in headwater reaches; width was assigned according to stream order elsewhere, with larger widths specified for reaches farther from the headwaters.
In addition to changes in model construction, model parameters were adjusted during the TMR model refinement. As part of the TMR routine the properties of the DCRM were directly translated; a subset of these parameters was modified during subsequent TMR model runs. One of the most important was recharge over the Pheasant Branch watershed. Recharge rates determined by surface-water modeling were input to the ground-water flow model via the MODFLOW recharge array. The surface-water model hydrologic response units (HRUs) were grouped such that hydrologic characteristics of an area (soil infiltration capacity, evapotranspiration, rainfall-runoff properties) were averaged into one representative value over the area; this grouping resulted in 21 recharge zones over the Pheasant Branch Watershed (fig. 3). Recharge rates ranged from a high of $9.5 \mathrm{in} / \mathrm{yr}$ to a low of $2.2 \mathrm{in} / \mathrm{yr}$ (table 1). This new recharge array corresponded to an area-weighted average recharge over the Pheasant Branch watershed 


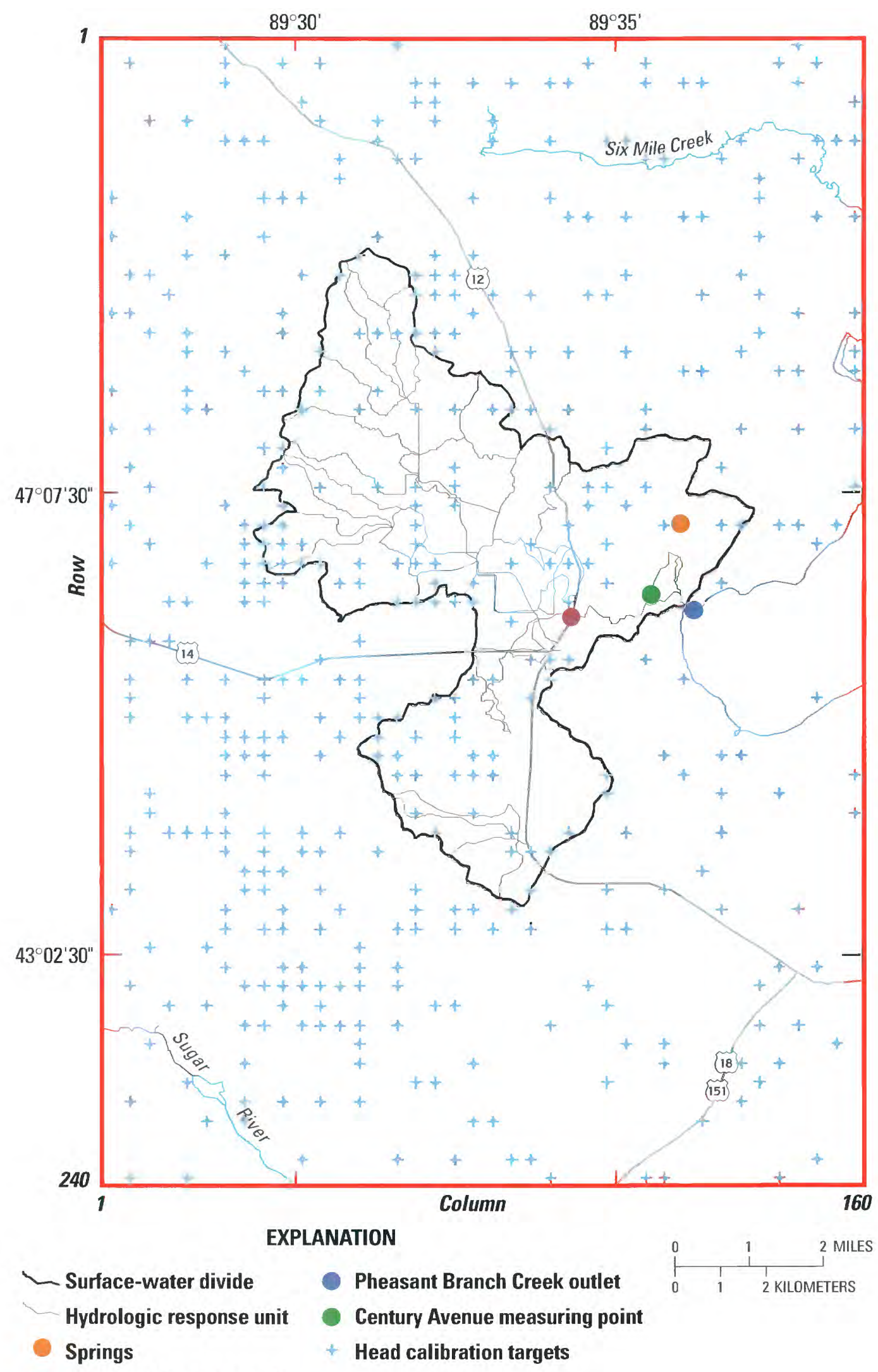

Highway 12 gaging station

Figure 3. Locations of the hydrologic response units (HRUs) used in the Pheasant Branch surface water modeling. (Head and flux targets used in the TMR model calibration are also shown.) 
of $8.0 \mathrm{in} / \mathrm{yr}$. It should be noted that this value is significantly higher than that used for the Pheasant Branch watershed in the regional Dane County Model (equal to $4.8 \mathrm{in} / \mathrm{yr}$ ). The original recharge array was considered theoretical, however (Krohelski and others, 2000; Swanson, 1996), and did not simulate baseflows for Pheasant Branch Creek very closely (see below).

Other significant changes to parameters included changes to horizontal hydraulic conductivity $\left(\mathrm{K}_{\mathrm{h}}\right)$ of the bedrock aquifers (layers 2 and 3), and increase of vertical leakage between the Springs and aquifers underneath the Springs (table 1). Leakage is defined as the flow of water from one hydrogeologic unit to another, and is input to the model through the specification of the VCONT array (McDonald and Harbaugh, 1988). The VCONT is a function of the vertical hydraulic conductivity and thickness of aquifers and confining units; higher values of VCONT indicate higher degrees of leakage. This refined model was then calibrated to the heads and fluxes used in the DCRM and additional flux data collected for the project. In particular, the calibration was aimed at more accurately simulating stream and spring discharge measurements while not significantly degrading the head calibration.

Although most of the discussion focuses on the TMR model, many of the refinements discussed here were input to the DCRM before the TMR perimeter boundaries were extracted. In addition to giving insight into the type of modifications needed in the TMR model to adequately simulate the hydrologic system, this procedure ensured that the most appropriate perimeter boundary was specified. That is, the Springs themselves are a regional feature (discharging more on a daily basis than any single municipal well in the county); thus the Springs could conceivably have measurable influence at a given TMR perimeter. Conceptual model refinements, albeit coarsely discretized, to the Dane County Regional Flow model before the model grid was refined helped ensure that boundary effects would be minimized.

\section{Parameter Estimation}

The TMR model was calibrated using parameter estimation techniques. The use of parameter estimation, or "inverse" models, for calibration is a relatively new advancement for the science, and numerous publications describe the advantages of inverse models (such as, Hill, 1992; Poeter and Hill, 1997; Hill, 1998). Briefly, the primary benefit of a properly constructed inverse model is its ability to automatically calculate parameter values (such as hydraulic conductivity) that are a quantified best fit between simulated model output and data measured in the real world (such as head and stream baseflow). Other benefits are also realized, such as the quantification of the quality of the calibration and a statistically rigorous measure of the uncertainty (that is, confidence interval) of predictions made using the optimized model. In addition, parameter correlation (such as hydraulic conductivity and recharge) and parameter sensitivity can be quantified and assessed. In this work, the TMR model in the Pheasant Branch area was coupled to the inverse code UCODE (Poeter and Hill, 1998).

One of the most important operations in parameter estimation is the selection of observations and associated weight given to these observations. There can be subjective aspects to the assignment, where the ultimate goal is obtaining an optimization evaluation that reflects the modeler's judgment of goodness of fit. Some have proposed using only measurement error to assign observation weights; in practice, however, the measured value can have additional, less quantifiable, sources of error. Primarily, these errors relate to how representative the measurement is to the condition being modeled. This model is simulating steady-state conditions when the hydrologic system is rarely at steady state. For example, measured head values can vary over tens of feet between years, and the location and elevation of the wells is often imprecisely known. Yet measurement error of head at a given well at a given time is roughly $0.01 \mathrm{ft}$. Therefore, the weights assigned to the head data are intended to reflect their representativeness, and take into account the fact that all head data were not collected at the same time and that there are uncertainties in the location and elevation of measurement. In addition, stream flows that are point measures in time may have an "excellent" ( \pm 5 percent accuracy) measurement rating, but knowledge of how well this measurement represents average conditions is unknown without a determination of flow duration. In addition, as shown in figure 3 there are many more measured head observations (454) in the model domain than the number of measured flux observations (4). Therefore, in practice, observation weights are not assigned using set criteria, but rather in such a way that the assessment of what constitutes a "best fit" in the parameter estimation routine (that, is the selection of an "optimal" model) is similar to the decision a modeler might make in trial-anderror calibration. 
The TMR model described above was optimized using the following criteria for head and flux targets in the Pheasant Branch area:

(1) The average flow $\left(Q_{50}\right)$ at the gaging station at Pheasant Branch Creek at Highway 12 was the most highly weighted observation because of the availability of the best flow duration information for the study period. The weight reflects the long flow record (continuously monitored from July 1974 through the study period) used to determine the flow duration at the site. The measured $\mathrm{Q}_{50}$ of $1.8 \mathrm{ft}^{3} / \mathrm{s}$ for 1974-98 was given a coefficient of variation $=0.01$ (=95-percent confidence interval that spans \pm 1 percent around the measured value). This value is more accurate than that reported by Holmstrom and others (1999) for the gage (fair, or \pm 15 percent) because the weight reflects its much higher quality on a relative scale to the other data used to optimize the model. That is, the weight represents the fact that we are willing to trade better results in other targets to have the optimization routine match this target well.

(2) A much smaller number of discharge measurements were made at the Pheasant Branch Creek at Century Avenue and at the Springs locations than at the Highway 12 gaging station. Therefore, these targets were given an intermediate weight, reflecting their shorter period of record and fewer discharge measurements (coefficient of variation $=0.3$ and 0.2 , respectively).

(3) A relatively long record of flow duration is available for Pheasant Branch Creek at the Lake Mendota Outlet, but these data were not collected contemporaneously with this study. Moreover, it is difficult to measure discharge accurately at this location because of lake backwater effects (D. Graczyk, USGS, oral commun., 1999). Therefore, these measurements were given less weight (coefficient of variation $=0.5$ ).

(4) Head measurements in the TMR model domain were given a low weight due to the uncertainty regarding their representativeness for the conditions simulated during calibration. These head data are the sum of all measured water levels for the area, but were not collected con- temporaneously. Rather, these data span 40 years. In addition, the head data are also less precisely located, both horizontally and vertically. Therefore, the resulting unfiltered head target data set often had multiple head values for a single node. Moreover, the measured head values for a single node might differ by over $100 \mathrm{ft}$. Clearly a finite difference model (such as one head value calculated per node) cannot simulate these data. The measured head data were filtered for use in the TMR model so that nodes with multiple measured values were replaced with the average of all head data for the node. Given these uncertainties, layer 2 head targets had a standard deviation equal to $10 \mathrm{ft}$, which equate to a 95 -percent confidence interval of $\pm 20 \mathrm{ft}$ around the measured value. Layer 3 head targets were weighted using a standard deviation equal to $25 \mathrm{ft}$, representing the additional uncertainty resulting from the wells being open to multiple aquifers and the potential unsteady nature of water levels in high capacity wells.

The parameters initially chosen for optimization included the hydraulic conductivity ( 6 zones in layer 1 , 1 zone in layers 2 and 3), vertical leakage of nodes immediately beneath the Springs, and the conductance of Lake Mendota littoral and deep lake sediments. Initial runs on parameter sensitivity showed the model was insensitive to changes in layer 1 hydraulic conductivity and lake bed conductance (fig. 4); that is, the measured observations used in the optimized calibration did not contain enough information to constrain these parameters. As a result, all subsequent runs used fixed values for these parameters based on the Dane County Regional Model and optimized only the remaining sensitive parameters.

\section{Stochastic Monte Carlo Analyses}

The effect of parameter uncertainty can be more formally addressed using stochastic approaches. While detailed discussion of stochastic techniques is beyond the scope of this work, a brief discussion follows. A Monte Carlo approach was used as a means to obtain the probability distribution of the capture zone of the Springs. This approach allows calculation of the probability of a certain occurrence, in this case the probability that the Springs will capture water from different parts of the model domain, given the uncertainty that exists 


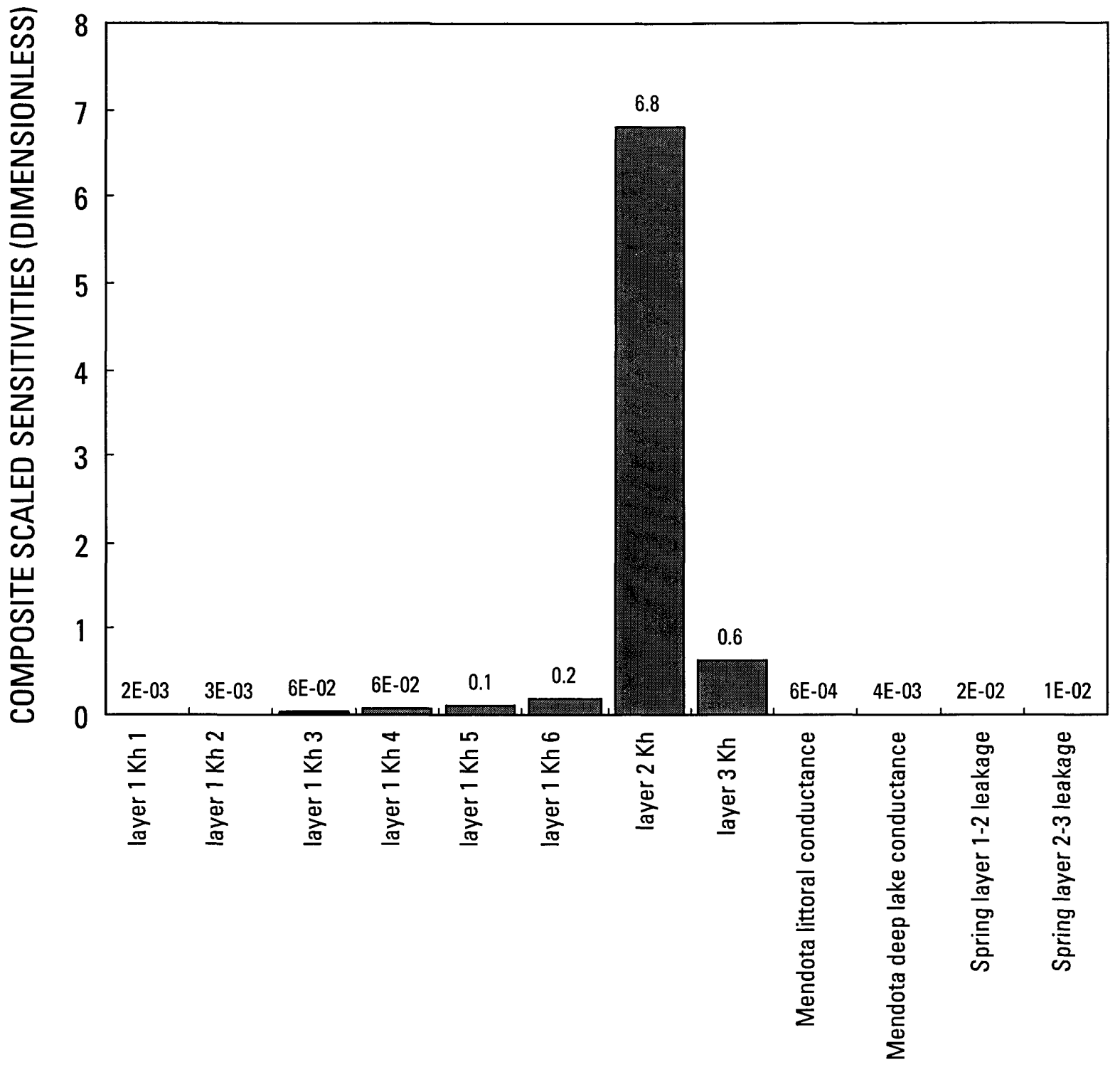

Figure 4. Plot of parameter sensitivity from the UCODE parameter estimation. (Horizontal hydraulic conductivity zones representing layer 2 , and to a lesser extent layer 3 , were the most sensitive parameters. Additional work with optimization and stochastic runs focused on modifications to these two parameters.)

for a discrete set of parameters. In this approach, a large number of MODFLOW model runs using the TMR model were performed using Stochastic MODFLOW (Ruskauff and others, 1998) while randomly varying the horizontal hydraulic conductivity of the upper bedrock aquifer (layer 2) and lower bedrock aquifer (layer 3) over reasonable ranges of values based on the results of UCODE optimization. In the case of layer 2, this range was uniformly distributed (all values are equally likely) between 1 and $15 \mathrm{ft} / \mathrm{d}$; layer 3 was uniformly varied between 0.7 and $10 \mathrm{ft} / \mathrm{d}$. Each run is called a "realization," and reflects one possible set of parameters for the model.

Because combinations of reasonable parameter values may yield unrealistic results, the head calibration statistics of the realizations were evaluated (or "conditioned") and unreasonable realizations were removed. Particle tracking was performed using Stochastic MODPATH (Ruskauff and others, 1998) in the Pheasant Branch watershed. This code utilizes output from the Stochastic MODFLOW realizations to delineate the recharge area of the Springs using a probability distribution where 1 is contributing in 100 percent of the real- 
izations, and 0 is contributing in 0 percent of the realizations.

\section{Geochemical Investigation}

Geochemical investigation focused on Springs and a nearby municipal well. The Springs area was divided up into 8 areas in the main spring complex, one additional spring located $1,300 \mathrm{ft}$ west of the main spring complex, and one ephemeral stream. Samples were collected for analysis of both ion and isotope chemical constituents. Major ions and nutrients were measured periodically from the Springs during March 1998 through April 1999. The municipal well was sampled once in August 1998. Springs and stream were sampled using a peristaltic pump; the municipal well was sampled from the pump well head. Unfiltered samples were used for field measurements of conductivity, temperature, dissolved oxygen and $\mathrm{pH}$, and lab measurements of alkalinity. Filtered samples $(0.45 \mu \mathrm{m}$ cellulose nitrate filter) were collected for determination of major ions, nitrate + nitrite $\left(\mathrm{NO}_{3}+\mathrm{NO}_{2}\right)$, ammonia $\left(\mathrm{NH}_{4}\right)$, total $\mathrm{N}$ and total dissolved inorganic phosphorus (DIP) analyses.

Because water and strontium isotope chemistry are not widely used in hydrological investigations, a short description, taken from Hunt and others (1998), is given here. Water isotopes (oxygen and deuterium) are ideal conservative tracers of water sources because they are part of the water molecule itself. Stable isotopes of water are conservative in aquifers at low temperature, but fractionate on the surface at less than 100 percent humidity (Gat, 1970). Because the vapor pressure of $\mathrm{H}_{2}{ }^{16} \mathrm{O}$ is greater than $\mathrm{H}_{2}{ }^{18} \mathrm{O}$, the residual liquid is characterized by a higher $\mathrm{H}_{2}{ }^{18} \mathrm{O}$ content after evaporation. Hydrogen and deuterium also fractionate, but to a greater extent due to larger percent mass difference. Thus, characteristic ${ }^{18} \mathrm{O} /{ }^{16} \mathrm{O}$ and ${ }^{2} \mathrm{H} /{ }^{1} \mathrm{H}$ ratios can fingerprint water sources. Strontium-87 is produced from radioactive decay of rubidium-87. Assuming a given initial ${ }^{87} \mathrm{Sr} /{ }^{86} \mathrm{Sr}$, minerals that have high $\mathrm{Rb} / \mathrm{Sr}$ concentration ratios will attain higher ${ }^{87} \mathrm{Sr} /{ }^{86} \mathrm{Sr}$ than minerals that have low $\mathrm{Rb} / \mathrm{Sr}$ concentration ratios. Biological or low-temperature abiotic processes do not significantly fractionate $\mathrm{Sr}$ isotopes; the isotopic composition of $\mathrm{Sr}$ (unlike that of the lighter elements) is entirely controlled by the mixing of $\mathrm{Sr}$ from geologic regimes having different isotopic composition (Graustein, 1989). Sr isotopes, when considered together with ion chemistry, can thus distinguish weathering reactions from cation exchange processes. This ability makes them suitable for water-rock interaction investigations (such as Bailey and others, 1996; Bullen and others, 1996) and discerning sources of water from isotopically distinct source areas (Eastin and Faure, 1970; Fisher and Steuber, 1976).

The major ions ( $\mathrm{Ca}, \mathrm{Mg}, \mathrm{Na}, \mathrm{K}, \mathrm{SO}_{4}$ ), total $\mathrm{P}$, nitrate+nitrite, $\mathrm{NH}_{4}$, and total $\mathrm{N}$ were analyzed by the University of Wisconsin Soil and Plant Analysis Laboratory and State Laboratory of Hygiene during the periods March 1998-October 1998 and November 1998April 1999, respectively. Alkalinity was analyzed by gran titration at the University of Wisconsin Water Chemistry Department. Chloride analyses were performed using liquid chromatography at the USGS, Middleton, Wisconsin. Analyses of water and strontium isotopes were performed at the U.S. Geological Survey National Research Program Laboratory in Menlo Park, California. Oxygen-18 values were measured using $\mathrm{CO}_{2}-\mathrm{H}_{2} \mathrm{O}$ equilibration (Epstein and Mayeda, 1953) on a Finnigan-Mat 251 mass spectrometer. Oxygen-18 values are reported in standard delta notation relative to Vienna Standard Mean Ocean Water (VSMOW). Analytic error $(2 \sigma)$ is estimated at \pm 0.1 per mil. Strontium isotope analyses were performed using the methodology described by Hunt and others (1998).

\section{RESULTS OF MODEL SIMULATIONS AND GEOCHEMICAL INVESTIGATION}

\section{Telescopic Mesh Refinement}

TMR modifications to the DCRM improved head and flux calibration for the Pheasant Branch watershed. The inclusion and more accurate depiction of nearby surface-water features (such as Brewery Creek, Dorn Creek, headwaters of Black Earth Creek) improved the DCRM head calibration in the area encompassed by the TMR model (table 2). The TMR area of the DCRM domain was slightly better calibrated than the overall DCRM model (root mean squared difference $=36.1 \mathrm{ft}$ in TMR area, $37.4 \mathrm{ft}$ for the overall domain-Krohelski and others, 2000). More notably, the recharge rate derived by the surface-water modeling significantly improved the flux calibration while only minimally degrading the head calibration (first TMR column versus last TMR column in table 2). Given the uncertainty associated with the accuracy of some of the head targets (such as significantly different observed values reported for the same model node) and the significant improve- 


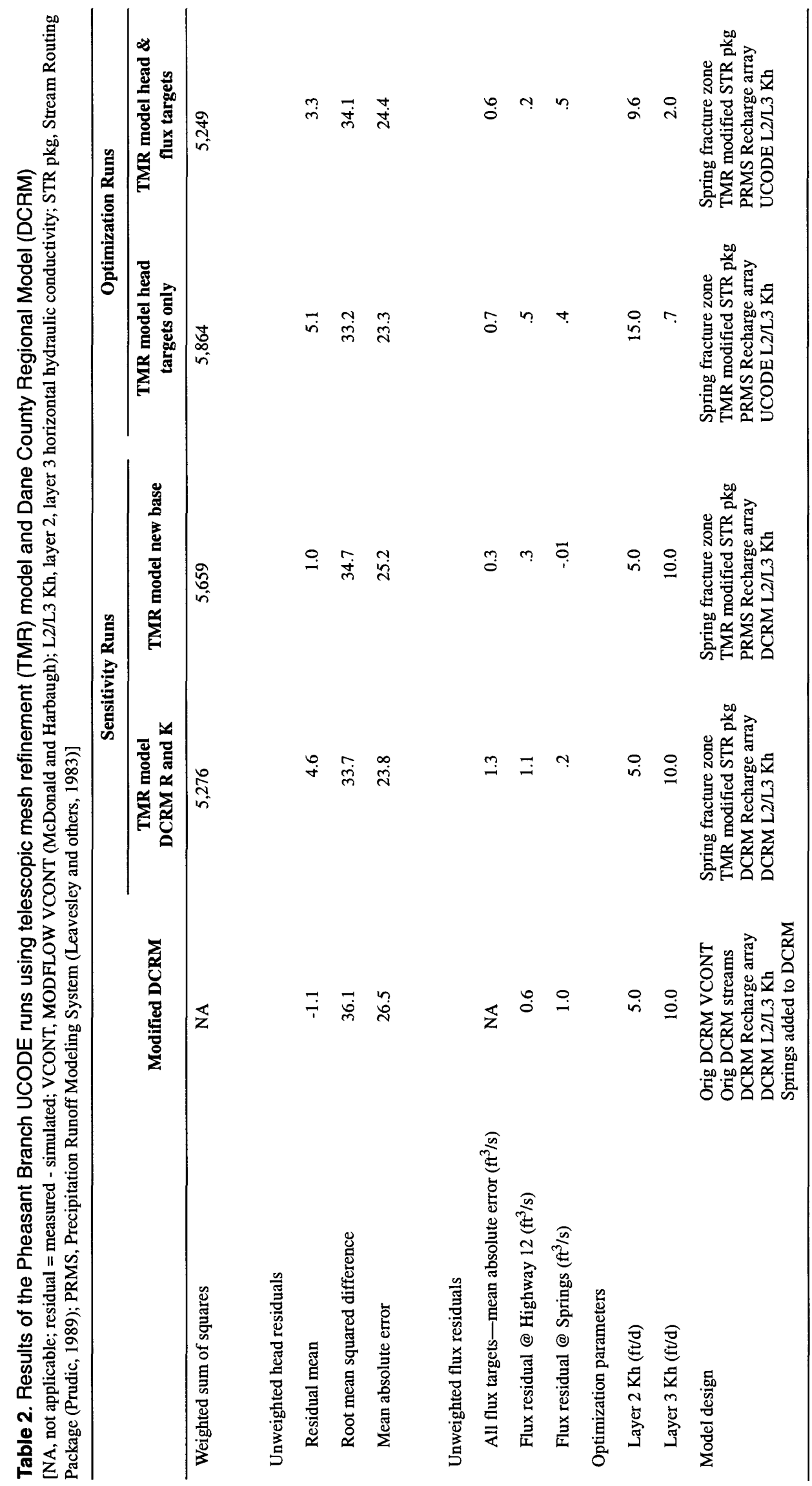


ment in simulated flux, the slight degradation in head calibration was considered to not invalidate the recharge array derived from the surface-water modeling.

The basin recharge rate is considered relatively well known (based on the surface-water modeling work), thus the recharge rate was fixed and horizontal hydraulic conductivity $\left(\mathrm{K}_{\mathrm{h}}\right)$ became the driver for head calibration. The DCRM used a sedimentologically based method for assigning conductivities (Swanson, 1996; Krohelski and others, 2000) that resulted in a large number of horizontal hydraulic conductivity $\left(\mathrm{K}_{h}\right)$ values to represent the conductivity field of layer 1 . A large number of values is not suitable for parameter estimation because each value requires three model runs to perform sensitivity analysis or optimization, which in turn results in unacceptably long run times and timeintensive data handling. As a means to assess the effects of changes to hydraulic conductivity, the $\mathrm{K}_{\mathrm{h}}$ values were grouped into eight $\mathrm{K}_{h}$ zones (table 1). Differences between the original DCRM $K_{h}$ field and the $K_{h}$ field created from the zones were negligible (that is, calibration statistics were identical to two significant figures). A sensitivity analysis was run on the eight $\mathrm{K}_{\mathrm{h}}$ zones and demonstrated that only the zone representing the $\mathrm{K}_{\mathrm{h}}$ of the upper and lower bedrock (layers 2 and 3 ) significantly affected the model results (fig. 4). This is not surprising in that much of layer 1 is dry in the Pheasant Branch basin, and all head targets are located in layers 2 and 3.

\section{Parameter Estimation}

The smaller number of $K_{h}$ zones allowed investigation of the TMR model using the parameter estimation program UCODE. During the optimization process a difficulty was encountered. The automatic routines of UCODE that perturb parameters and run MODFLOW in batch mode have an unfortunate artifact-the perturbation required by UCODE can cause the stable base MODFLOW model to become unstable and not converge. This in turn will result in a failed UCODE run. If the modeler chooses to continue on without convergence (an option in Groundwater Vistas) the UCODE routine will successfully complete. However, the UCODE optimization evaluation may include a nonconverged model run that ended with an iteration that yields an unrealistic model (such as poor mass balance). Because the model is re-run and model output files overwritten, it can be difficult to discern if non-conver- gence occurred. In the TMR model runs, non-convergence was caused by location and high conductance of a subset of fixed-stage stream nodes in the Stream Routing Package (STR). High values of stream conductance effectively transmit the effects of the headwater stream nodes to the ground water (and vice versa), which can cause oscillations in the ground-water solution. This can cause segments of headwater streams to dry and wet sporadically. The model solution at the end of the maximum number of iterations often had inaccurate simulated stream flows that were used by UCODE to formulate the new (poorly based) parameter values. Removing a small set of headwater STR nodes overcame the instability at higher $\mathrm{K}_{\mathrm{h}}$ values. It should be noted that the problems would likely be worse if constant flux or general head boundary conditions are used instead of constant head nodes at the model perimeter because constant head boundary conditions fix heads at the perimeter, that, in turn, tend to dampen the oscillation within the model domain.

When only head targets were used to obtain the optimal calibration, the head residual was minimized (fig. 5) and resulting $K_{h}$ values were three times higher than the DCRM for layer 2, and over ten times lower for layer 3 (table 2). As might be expected when flux targets are not considered, the measured $\mathrm{Q}_{50}$ fluxes are poorly simulated (fig. 5). When heads and flux targets are considered the optimization routine obtains a minimum in the residual sum of square error (table 2, fig. 5) but increases for $\mathrm{K}_{\mathrm{h}}$ of layer 2 to nearly twice the DCRM value, and decreases $K_{h}$ of layer 3 to roughly one-fifth the DCRM value (table 2). This yields the "optimal" solution for these targets and weights, but should be considered with the following caveats.

Unweighted calibration results might indicate biases in the head data used for calibration. For example, the mean error values (table 2) indicate simulated head values are consistently too low (the residual sign is positive) in all TMR model runs. While the result could be interpreted as the need for increased recharge and/or lower $\mathrm{K}_{\mathrm{h}}$, it could also be a result of biases in the measured head data and inconsistencies in how well they represent the regional water levels. The latter might be expected because the TMR model domain contains a large extent of the end moraine and Driftless areas. These areas are expected to have more perched ground water (Krohelski and others, 2000), and are likely responsible for the large range of water levels reported for a single model node. In addition, perched water level errors are always biased towards higher heads (that is, 


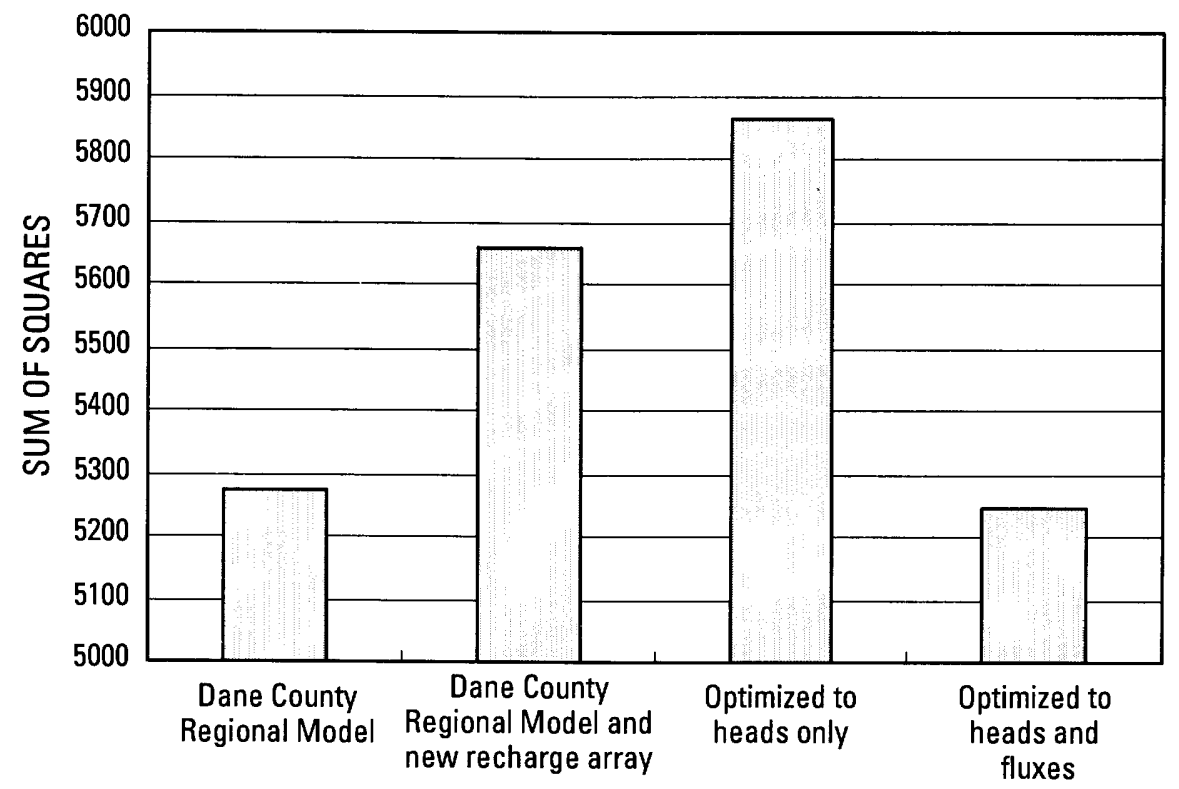

Figure 5a. Plot of sum of squares residual for UCODE optimization. (Note that although there are many more head targets than flux targets, the weight assigned the flux target at Highway 12 results in an overall worse fit when only head targets are considered.)

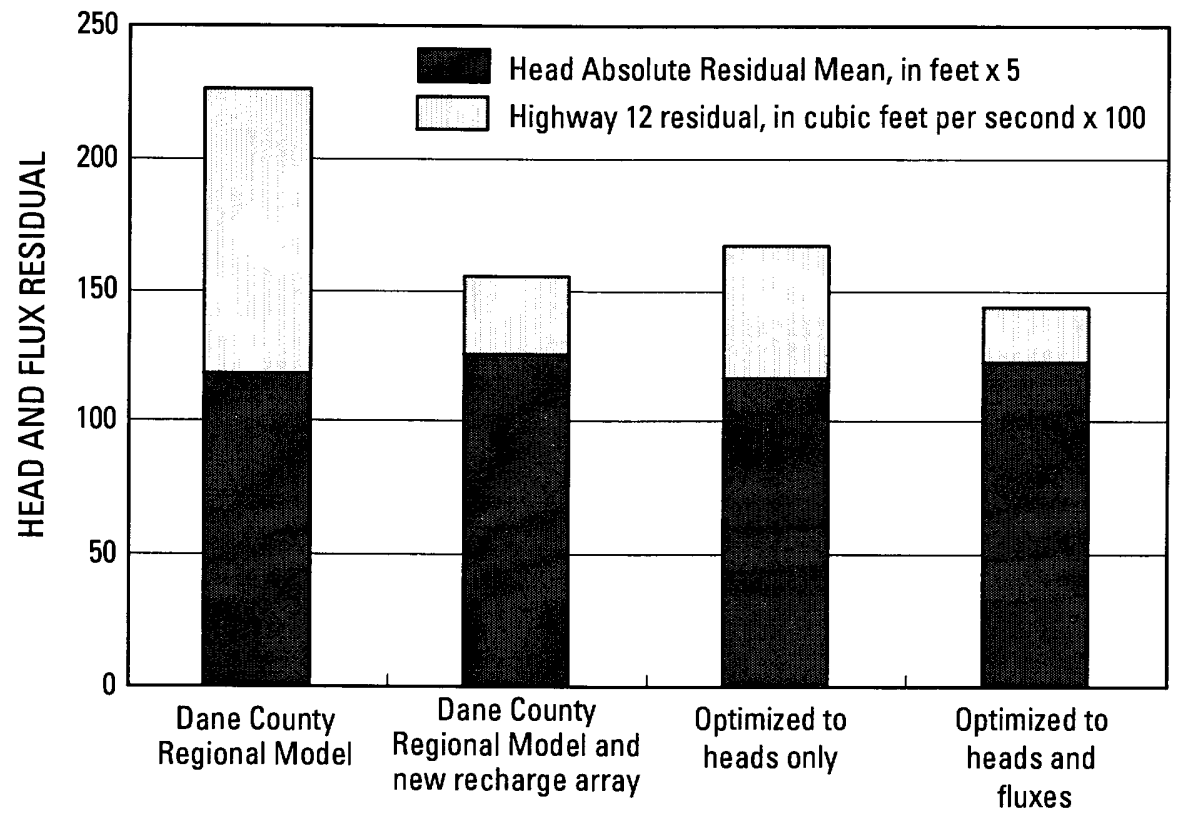

Figure 5b. Plot of residuals from all head calibration targets and the flux residual at Pheasant Branch Creek at Highway 12. 
perched water levels will always be above the regional water table). While not within the scope of this work, critically evaluating and filtering the head calibration targets is a subject of ongoing work. The parameter estimation routines use weighted statistics based on a sum of squares residual calculation that is more resistant to the biases described above.

There is other evidence that suggests that the $\mathrm{K}_{\mathrm{h}}$ of layer 2 and 3 is similar to that estimated by UCODE in the model area. Layer 2 bedrock includes a carbonate aquifer that outcrops throughout the area and is characterized by extensive fracturing and dissolution; conductivities for Cambrian sandstones elsewhere in Wisconsin have also been on the order of that reported by the UCODE optimization (Young, 1992). However, it is also possible that the optimization might have been overly controlled by the high weight given to the Highway 12 gaging station data. For example, layer 3 has only five head targets, and they are dominated by water levels from high capacity wells. The heads reported are uncertain (thus given lower weight in the optimization) due to problems with representativeness of water levels obtained from pumping wells (Driscoll, 1986). These problems are a result of confounding factors such as well-loss effects, and the fact that the wells are often open to multiple aquifers (Krohelski and others, 2000). In this case, the optimization of layer 3 is being affected more by how changes in $\mathrm{K}_{\mathrm{h}}$ affect the distribution of flow between locations measured by the flux targets and deep underflow to Lake Mendota than the head calibration in layer 3.

Flux simulation was also refined in the TMR modeling. Preliminary investigation was performed using the DCRM and included both changes to the recharge array and the degree of vertical leakage between layers 2 and 3 near the Springs. The use of the DCRM was advantageous because the Springs are a regional hydrologic feature, thus are suitable for the larger grid spacing of the DCRM. Any changes that were required could be first tested for efficacy and reasonableness without the concern of boundary violations and added work of translating all changes to the TMR model. Based on this work, modifications to the recharge array derived from the surface-water model were deemed reasonable and simulated flows at the Highway 12 gaging station were much improved. Spring discharge was improved by the new recharge array although it was noted that Spring flows could not be simulated using only layer 2 capture. It was concluded that maintaining a tight confining unit between the lower bedrock aquifer and upper bedrock aquifer in the area of the Springs could not yield sufficient water to simulate measured spring discharge given the present understanding of the recharge distribution. An increase to the degree of vertical leakage between the deep sandstone aquifer (layer 3) and the upper Paleozoic bedrock (layer 2) was investigated using the DCRM; this work indicated that a breach in the Eau Claire confining unit could explain high Spring discharge. Modifications to the degree of leakage between layers 2 and 3 were further investigated using the TMR model.

Spring discharge was improved by the new recharge array and modifications to the location of the Eau Claire Shale confining unit. In the TMR model, modifications to layer 2-3 vertical hydraulic conductivity $\left(\mathrm{K}_{\mathrm{v}}\right)$ were restricted to nodes near the Spring (table 1, fig. 6). In the larger springs area, $16 \mathrm{TMR}$ nodes were assigned a vertical leakage equal to a value typical for the Lake Mendota area where the Eau Claire shale is absent (table 1, fig. 6). In addition, one TMR node immediately beneath the Spring was assigned a higher $\mathrm{K}_{\mathrm{V}}$ (such as might be expected from a prominent vertically orientated fracture zone); the vertical leakage value assigned to this node (VCONT $=0.14$, table 1 and fig. 6) roughly corresponds to assigning the $\mathrm{K}_{\mathrm{V}}$ of layers 2 and 3 a value five times that used in the DCRM. While the entire area modified is restricted to the size of one DCRM node (1,312 ft by $1,312 \mathrm{ft}$ ), the exact location where the Eau Claire confining unit is absent is poorly understood in this area. It is conceivable that this area extends from the Springs to the area near Lake Mendota where the Eau Claire was missing in the DCRM (fig. 6). This is a potential topic for investigation, and may be addressed in future work in the Pheasant Branch.

Overall simulation of fluxes in the TMR model was significantly improved from the unmodified DRCM (table 2). Flux at the Highway 12 gaging station improved from being 60 percent under-simulated to within measurement error (11 percent under-simulated) in the optimized case. Further improvement in simulated fluxes by UCODE optimization was limited by the parameters chosen for optimization. That is, recharge was not varied in the UCODE runs, and optimization proceeded by changing only hydraulic conductivities of layers 2 and 3. This approach is not as powerful as changing recharge rates, and global optimization is obtained by balancing the improved head calibration against degrading the flux calibration at Highway 12 . Moreover, the simulated flux in the Springs was more 


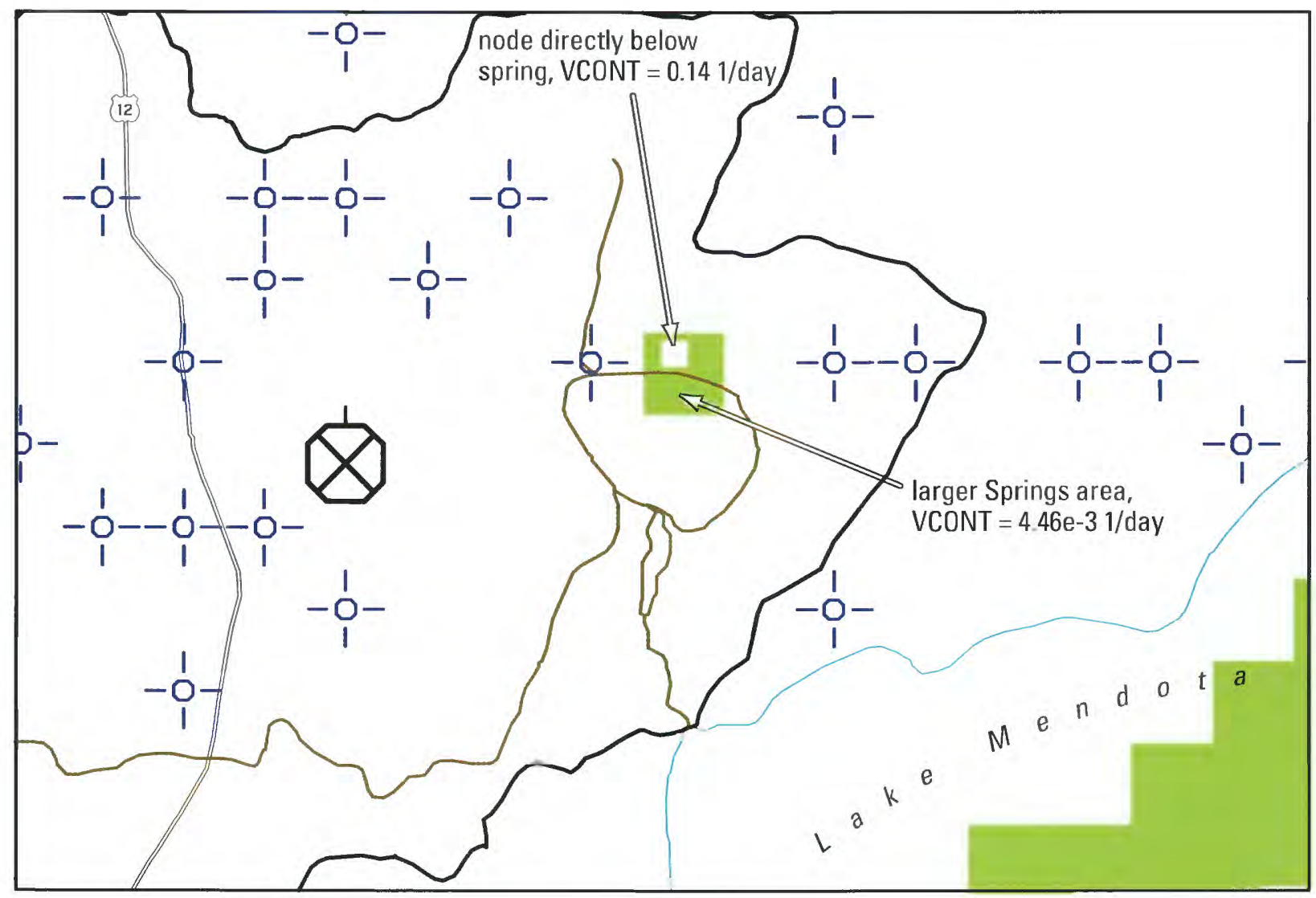

EXPLANATION

Area where Eau Claire shale is absent

Ephemeral stream

Surface water divide

$\bigotimes$ Middleton Well \#4

-' - Head calibration point

Figure 6. Area where the connection between layers 2 and 3 was modified in the telescopic refinement model is shown above. (The "larger Springs area" represents one DCRM node with vertical leakage equal to areas where the Eau Claire confining unit is absent (for example, Lake Mendota). The "node directly below Springs" corresponds to one TMR node that represents a vertical fracture conduit enhanced by dissolution. Larger VCONT values correspond to larger leakage.) 
closely simulated in the runs that used the DCRM higher $\mathrm{K}_{\mathrm{h}}$ of layer 3, but simulated flow at Highway 12 was worse. This case was not considered the optimal model because (1) the flow duration record at the Highway 12 gaging station ( 24 years) was of better quality than the Spring discharge record (2 months), and (2) the surface-water modeling work and resulting recharge array focused on the areas upstream of Highway 12; the Springs capture zone encompasses a significant area outside the area studied in the surface-water modeling work (see below). These areas outside of the Pheasant Branch surface-water basin were, by default, assigned the lower flux rates of the original DCRM recharge array.

Given the model results presented above, it is apparent that there is not a single set of parameters that can best simulate all facets of the Pheasant Branch system. The regional DCRM had an acceptable calibration to head and flux over the entire county. Calibration of the TMR model to heads alone indicates that layer 2 should have higher conductivity and layer 3 should have lower conductivity for the Pheasant Branch area than specified in the DCRM. Calibration to heads and fluxes suggests that the DCRM values should be altered less than suggested by a calibration to heads alone, but the values are still different than the DCRM. None of the values can be easily dismissed as unreasonable, and different parameter sets might be explained by differences in scale, preferential flowpaths/spatial heterogeneity of hydraulic conductivity, and uncertainty in the measured data (such as wide variety in measured head for a single node, short flow duration records from some flux targets). While such areas will be topics of future work, stochastic methods can be used with the present understanding to address the effects of this parameter uncertainty on predictions.

\section{Stochastic Monte Carlo Analyses}

Stochastic methods are ideal for incorporating the uncertainty in $\mathrm{K}_{\mathrm{h}}$ for layers 2 and 3 because they are designed around the concept of probability. Similar to flipping a coin a large number of times to obtain probability of heads versus tails, a large number of model simulations can be run varying $\mathrm{K}_{\mathrm{h}}$ to assess the probability of different head and flow configurations. By analyzing the set of model results, an assessment of the results and the uncertainty in predictions can be obtained. In this application the $K_{h}$ of layer 2 and layer 3 were allowed to vary within the range specified by the UCODE optimization - between 5 and $15 \mathrm{ft} / \mathrm{d}$ for layer 2 and between 0.7 and $10 \mathrm{ft} / \mathrm{d}$ for layer 3 . Because there are no data to suggest which of the values are more likely, the simulations were set up such that all values within the range were equally likely (that is, a uniform distribution). There are no set rules for the number of runs needed to adequately characterize the problem, however an analysis of changes to the mean absolute error (MAE) in head showed that the problem had stabilized at 200 realizations (fig. 7a). A check of the model using 300 realizations and a different random number seed also confirmed that 200 realizations were sufficient. Examination of the variability in absolute mean head difference for 200 realizations shows the presence of outlier combinations that clearly do not yield a calibrated model (fig. 7b). These outliers point out the need for filtering the 200 runs such that only reasonable models are left for predictions.

This filtering (or "conditioning" in Monte Carlo parlance) was performed using the head MAE. The UCODE results in table 2 are considered reasonable model results - of those results the highest acceptable MAE was $25.2 \mathrm{ft}$. Therefore, this was the cutoff value for conditioning; realizations with an MAE less than or equal to 25.2 were passed and included in the predictive runs. Of the original 200 realizations, 136 realizations met this criterion. The automated routine in Groundwater Vistas can only condition based on head results, therefore the reasonableness of these 136 realizations with respect to flux calibration was not assessed. However, this was not considered problematic because none of the simulated fluxes using the surface water-derived recharge array in table 2 are grossly out of calibration, and the effects on simulated fluxes are expected to be less sensitive than if recharge rates were included in the stochastic runs.

The stochastic runs were summarized by performing statistics and particle tracking on the conditioned runs. Mean heads are the average heads in the 136 realizations; the standard deviation addresses the variability of simulated heads. These results show a reasonable distribution of head, with the largest variation in simulated heads away from surface-water features or near pumping wells (figs. $8 \mathrm{a}$ and $8 \mathrm{~b}$, respectively). The conditioned heads and cell-by-cell flows can also be used to perform particle tracking with a stochastic version of the USGS program MODPATH. In this application the program computes the probability that specified particles are captured by a boundary condition of interest. In the stochastic code used here, no MODPATH variables 


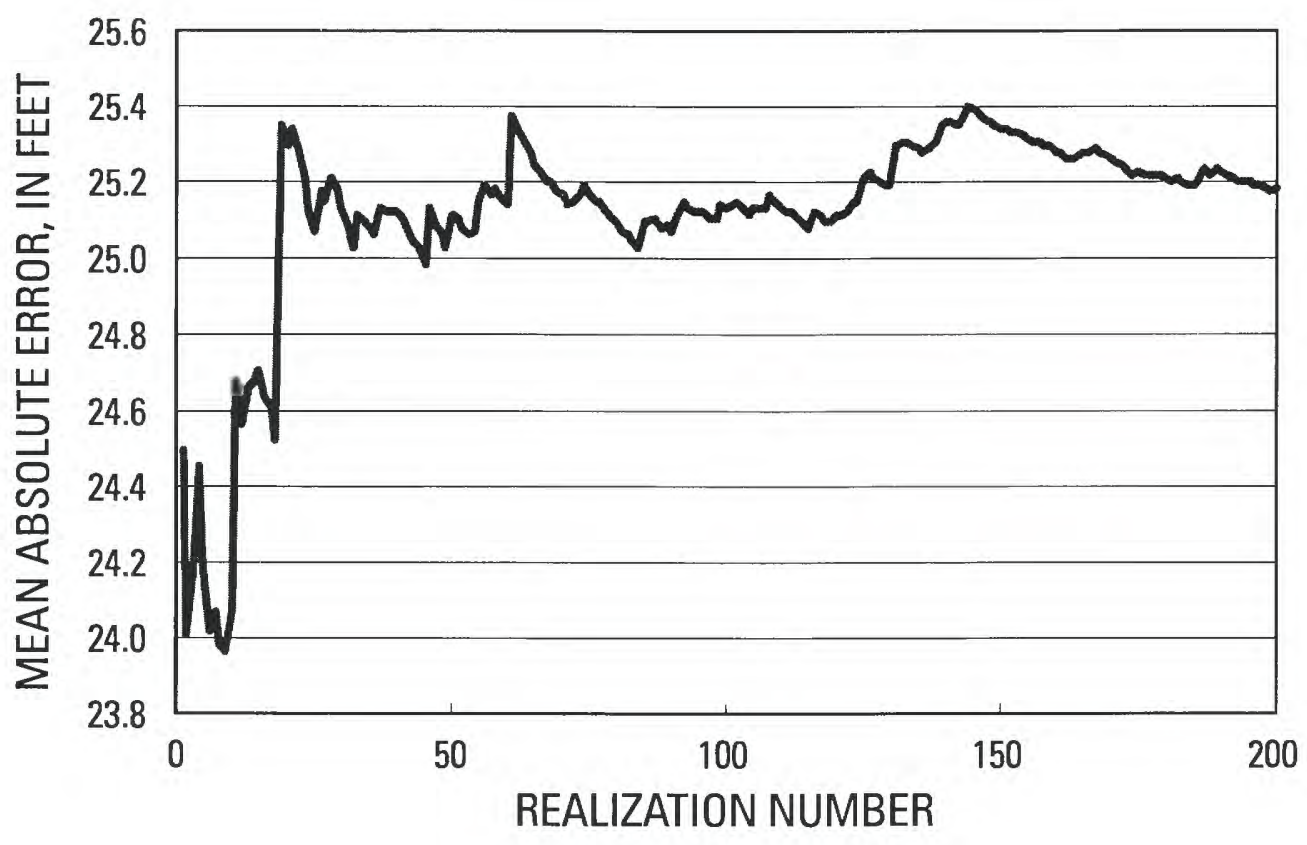

Figure 7a. Cumulative mean absolute error (heads) for 200 realizations of Stochastic MODFLOW. (Horizontal hydraulic conductivity of layers 2 and 3 varied between 5 and $15 \mathrm{ft} / \mathrm{d}$ and 0.7 and $10 \mathrm{ft} / \mathrm{d}$, respectively.)

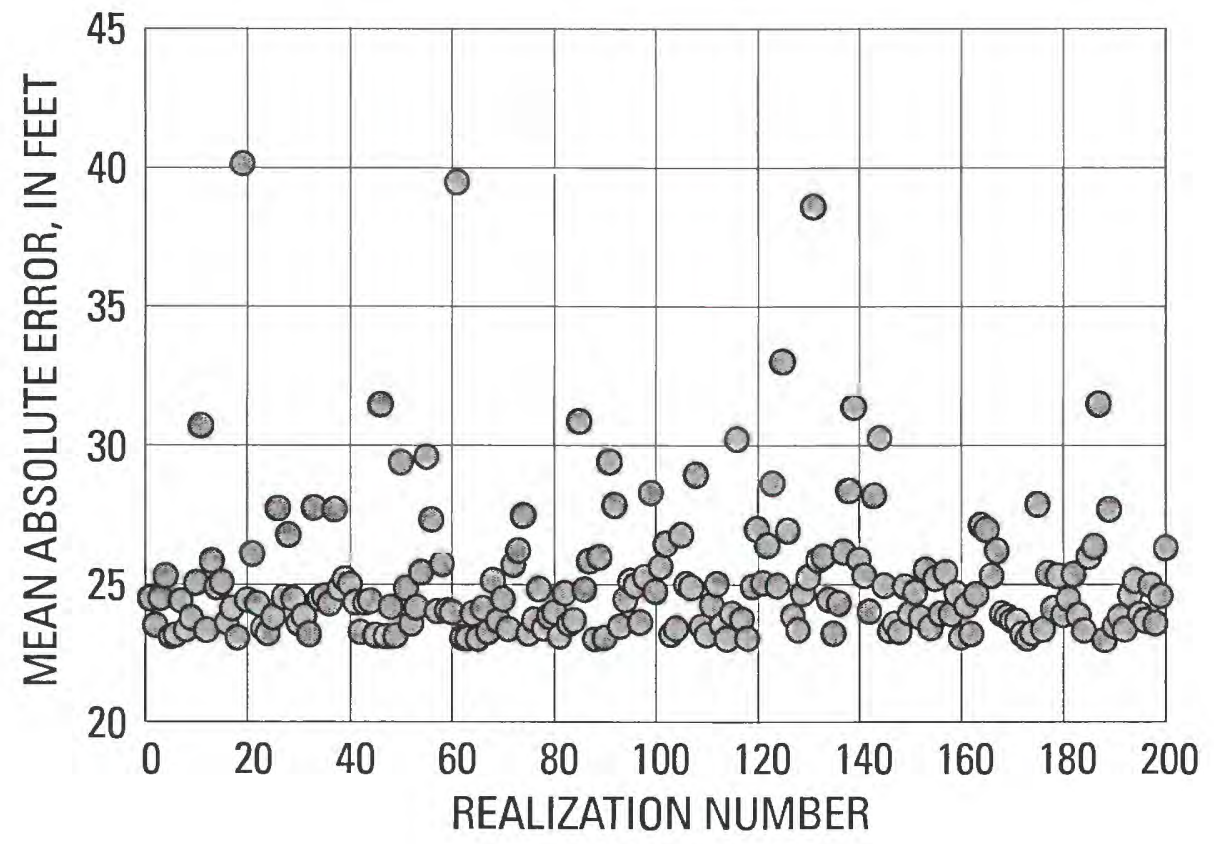

Figure $7 \mathbf{b}$. Scatter plot of mean absolute error (heads) for each of the 200 realizations of Stochastic MODFLOW. (Horizontal hydraulic conductivity (Kh) of layers 2 and 3 varied between 5 and $15 \mathrm{ft} / \mathrm{d}$ and 0.7 and $10 \mathrm{ft} / \mathrm{d}$ respectively. The plot illustrates the presence of outlier combinations of $\mathrm{Kh}$ that result in an uncalibrated model.) 
are considered uncertain and all uncertainty is assumed to occur in the MODFLOW results. In this application, capture probability was calculated using particles placed near the top of layers 2 and 3 in the northern half of the model domain; the stream node representing the Springs was used to tabulate capture.

Based on the model results, the Springs' recharge area includes areas outside its immediate surface watershed (figs. 9a and 9b) demonstrating that the ground watershed and surface watershed do not coincide. The majority of the Springs' recharge area is within the larger Pheasant Branch Creek watershed illustrating the strong connection between the North Fork of the Pheasant Branch and the Springs. The fact that the DCRM capture zone for layer 2 (fig. 1) approximates the TMR capture zone for layer 2 (fig. 9a) underscores the regional nature of problem. The longest travel times (from the farthest reaches of recharge area) are on the order of thousands of years. The stochastic results show that the uncertainties in $K_{h}$ of layers 2 and 3 have relatively isolated effects on the north and west edges of the Springs' recharge area. Moreover, the layer 3 capture zone is larger than and encompasses all of the layer 2 capture zone demonstrating the reduced effects of competing water sinks (such as nearby streams) in the deeper layer.

Although the global hydrologic leakage between layer 2 and 3 was not explicitly included in sensitivity/optimization/stochastic runs, the larger layer 3 capture zone can be thought of as a conservative estimate of the Springs' capture. Changes to the vertical leakage between layers 2 and 3 were not formally considered due to a lack of data on the Eau Claire confining unit properties/occurrence and sparse head data in the deep sandstone aquifer (layer 3 ). As a result the TMR model used unmodified calibrated values from the DCRM.

However, it is conceivable that there is a higher leakage between the layers. If this were the case, water could flow to the deeper layer instead of laterally flowing to competing water sinks (such as Dorn and Pheasant Branch Creek) in areas where there is capture in layer 3 but not layer 2; the layer 2 capture zone shown in figure 9a would be more applicable if the leakage between the layers 2 and 3 were smaller (tighter). Because the layer 3 capture zone encompasses the whole of the layer 2 capture zone, it is more likely to encompass the range of leakage between layers 2 and 3 .

\section{Geochemical Investigation}

The water in the Pheasant Branch Springs area is calcium-magnesium-bicarbonate type (table 3 ), the most common type in natural waters (Stumm and Morgan, 1981). Locally, other ions can be important (such as nitrate in Frederick Springs 1 and 2, table 3). As demonstrated by the small standard deviations reported in table 3 , the variation in water chemistry over time at a given sampling location in the Pheasant Branch Springs area is relatively small. There are, however, notable differences in chemistry sampled at the Frederick Spring complex, the Gate Spring, and the Culvert Crossing surface-water runoff location (fig. 10) that are described below.

One of the most notable findings of the geochemical sampling was the large spatial variability of the Frederick Springs throughout the sampling period; there were large differences observed between the west (Frederick Springs 1 and 2) and east (Frederick Springs 5 and 6) portions of the Springs, even though the spring vents 1 and 6 are located within $50 \mathrm{ft}$ of each other (table 3, figs. 11 through 14). The difference in spring chemistry is gradational such that Frederick Springs 3 and 4 are intermediate between the west and east spring water type. Moreover, this pattern holds for total dissolved solids as measured by specific conductance (fig. 11), major ions (such as fig. 12), as well as strontium (fig. 13) and oxygen (fig. 14) isotopes. In most cases the variability within the Frederick Springs is larger than that between Frederick Springs and a spring that was sampled 1,300 ft away (Gate Spring, table 3).

The water chemistry differences observed in the springs are attributed to changes in location in the recharge area. Ground-water flow occurs in "flow tubes" that extend from the recharge areas to the discharge point. These tubes do not cross, and can be delineated using flow net analysis (Freeze and Cherry, 1979) or particle tracking in numerical modeling. Once a contributing area is defined, the relation between recharge area and discharge point chemistry (that is, spring vent chemistry) can be made.

In the case of the Frederick Spring system, there is evidence for different conditions in the recharge areas influencing the water chemistry observed at the spring vent. The calcium distribution (fig. 12) and strontium isotope (fig. 13) plots can be combined to show a twocomponent mixing diagram where the two end members are Ordovician carbonate dominated water in the western spring vents (Frederick Springs 1, 2a and 2b in 

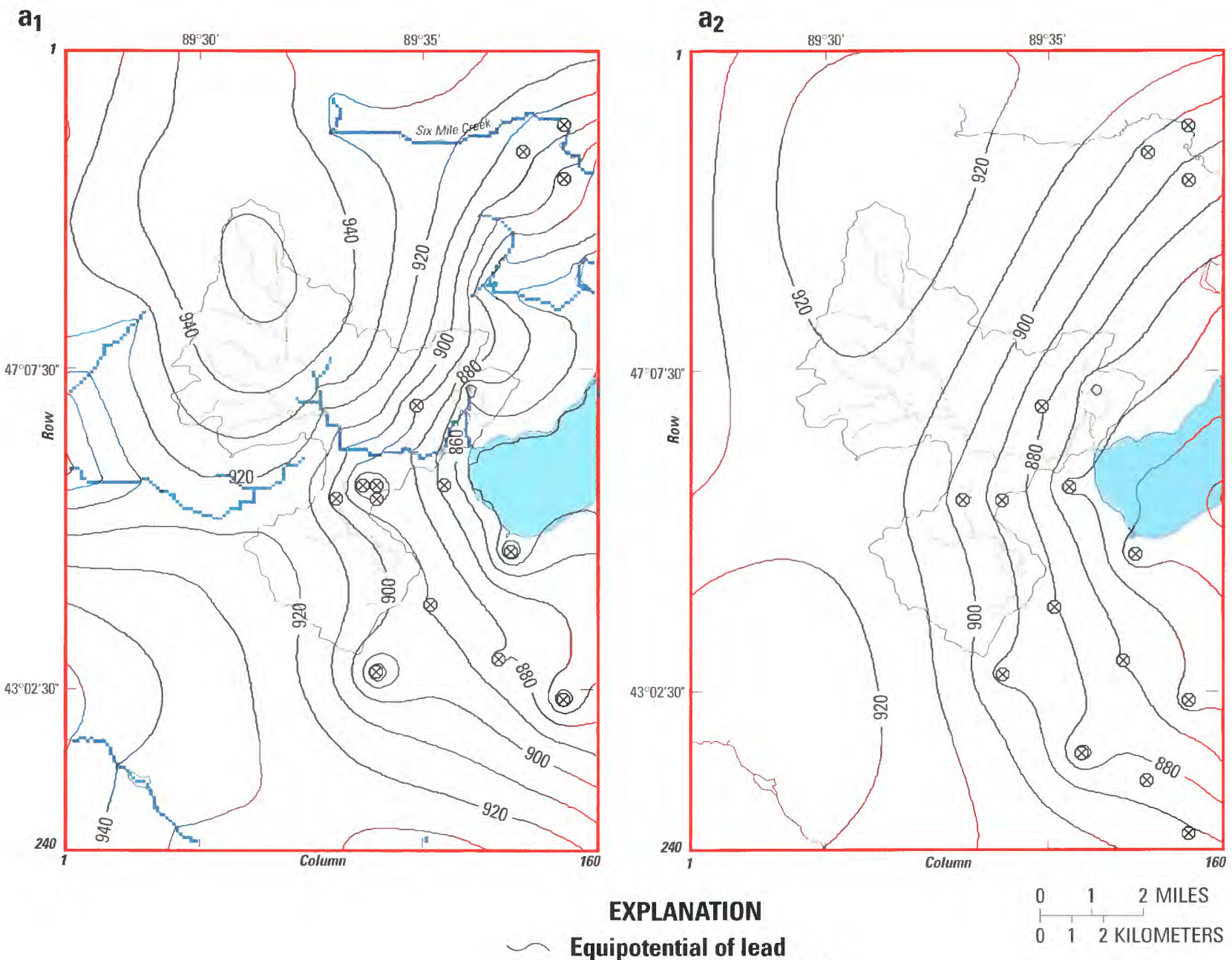

\section{Equipotential of lead contour-10-foot interval}

$\otimes$ High capacity well

Figure 8a. Results of conditioned stochastic MODFLOW runs for the upper bedrock aquifer $\left(\mathrm{a}_{1}\right.$, model layer 2$)$ and the lower bedrock aquifer $\left(a_{2}\right.$, model layer 3$)$. (The figures show mean heads for the 136 realizations; the mean absolute error equals $23.78 \mathrm{ft}$.) 

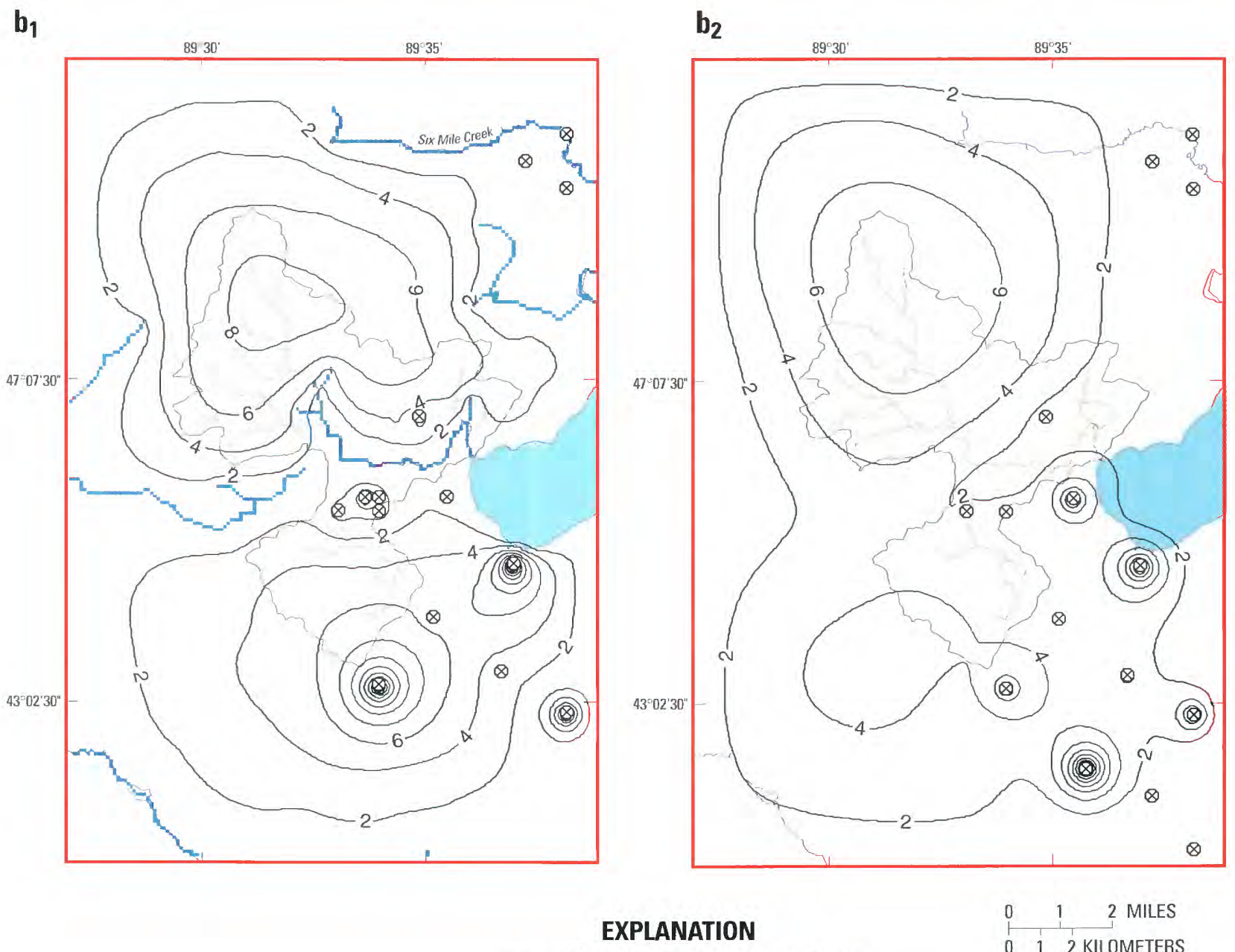

\section{EXPLANATION}

Standard deviation contours

for head distribution-

2-foot interval

\&igh capacity well

Figure $8 b$. Results of conditioned stochastic MODFLOW runs for the upper bedrock aquifer $\left(b_{1}\right.$, model layer 2$)$ and the lower bedrock aquifer $\left(b_{2}\right.$, model layer 3 ). (The figures show standard deviation contours for the head distribution shown in figure $8 \mathrm{a}$. The largest variations in head are near pumping wells and away from the surface water.) 


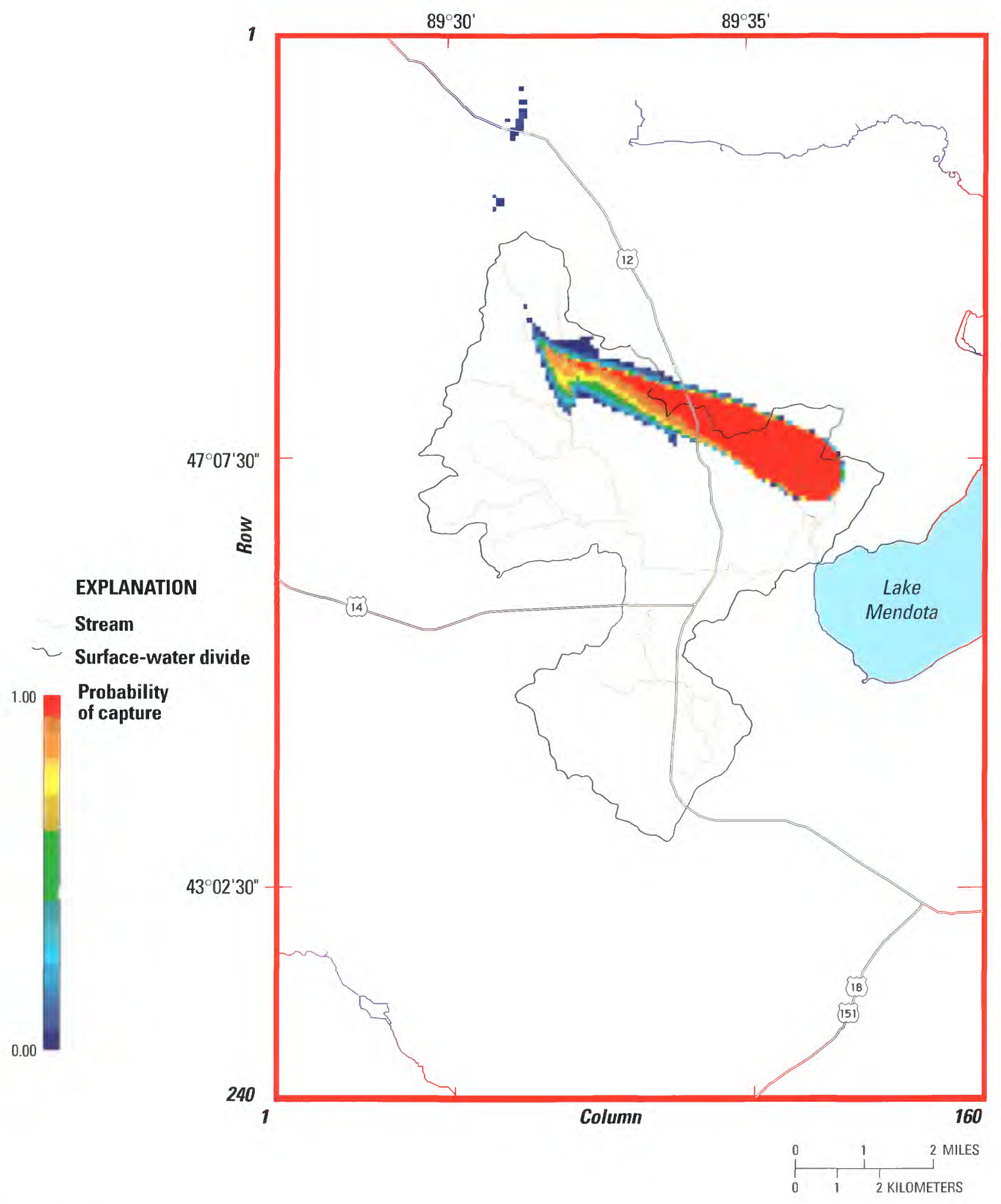

Figure 9a. Results of conditioned stochastic MODPATH runs for the upper bedrock aquifer (layer 2). (The probabilistic capture zone for the Frederick Springs area is calculated by tracking particles placed near the top of layer 2 and tabulating if the particles are captured by the simulated spring. A value of 1 represents capture in 100 percent of runs. The capture zone is smaller than figure $9 \mathrm{~b}$ because of stronger effects of competing hydrologic sinks (for example, other surface-water features) in layer 2 than in the deeper layer 3. In addition, the TMR model compares well to the capture zone delineated by the DCRM in figure 1) 


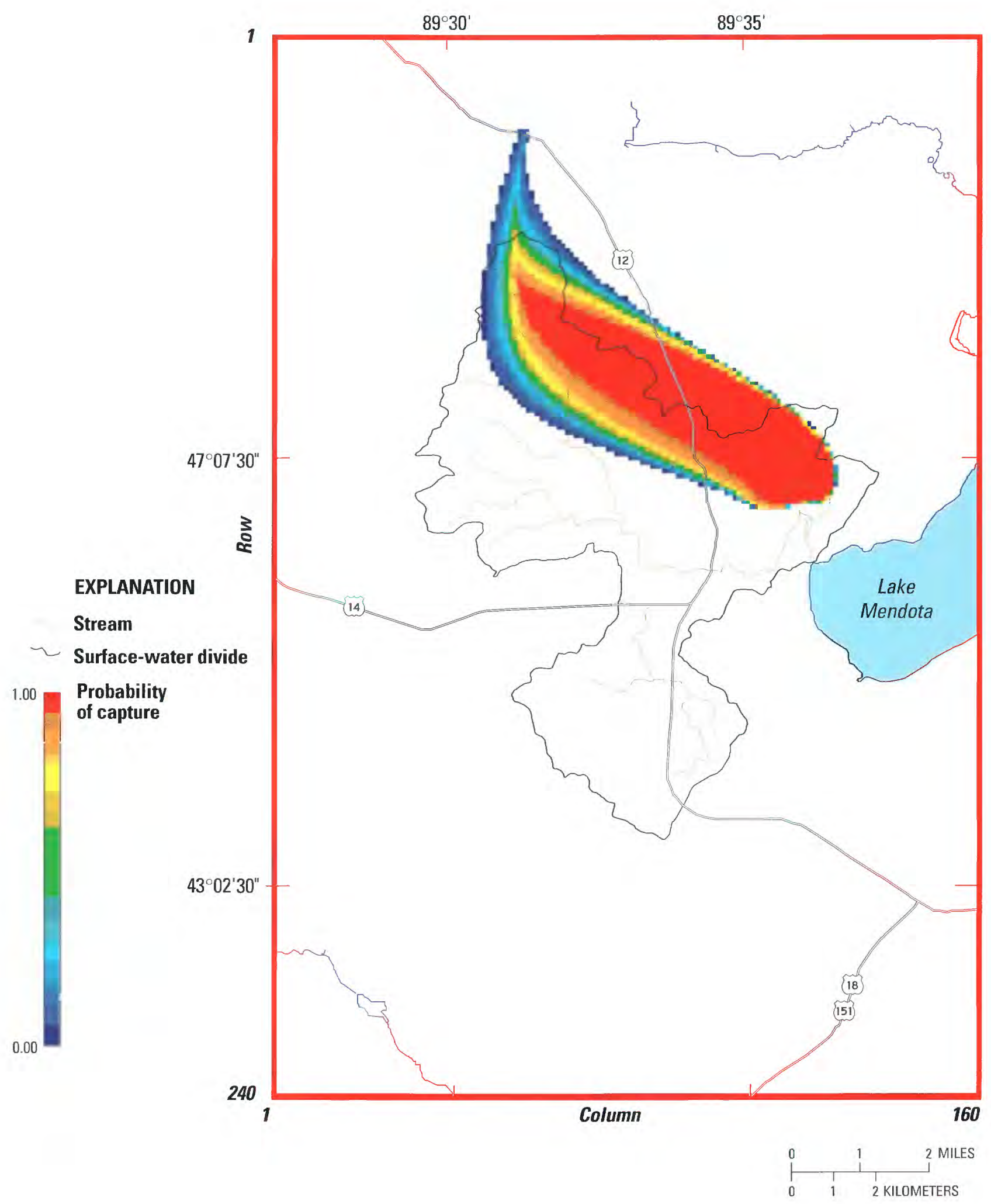

Figure 9b. Results of conditioned stochastic MODPATH runs for the lower bedrock aquifer (layer 3). (The probabilistic capture zone for the Frederick Springs area is calculated by tracking particles placed near the top of layer 3 and tabulating if the particles are captured by the simulated spring. A value of 1 represents capture in 100 percent of runs.) 


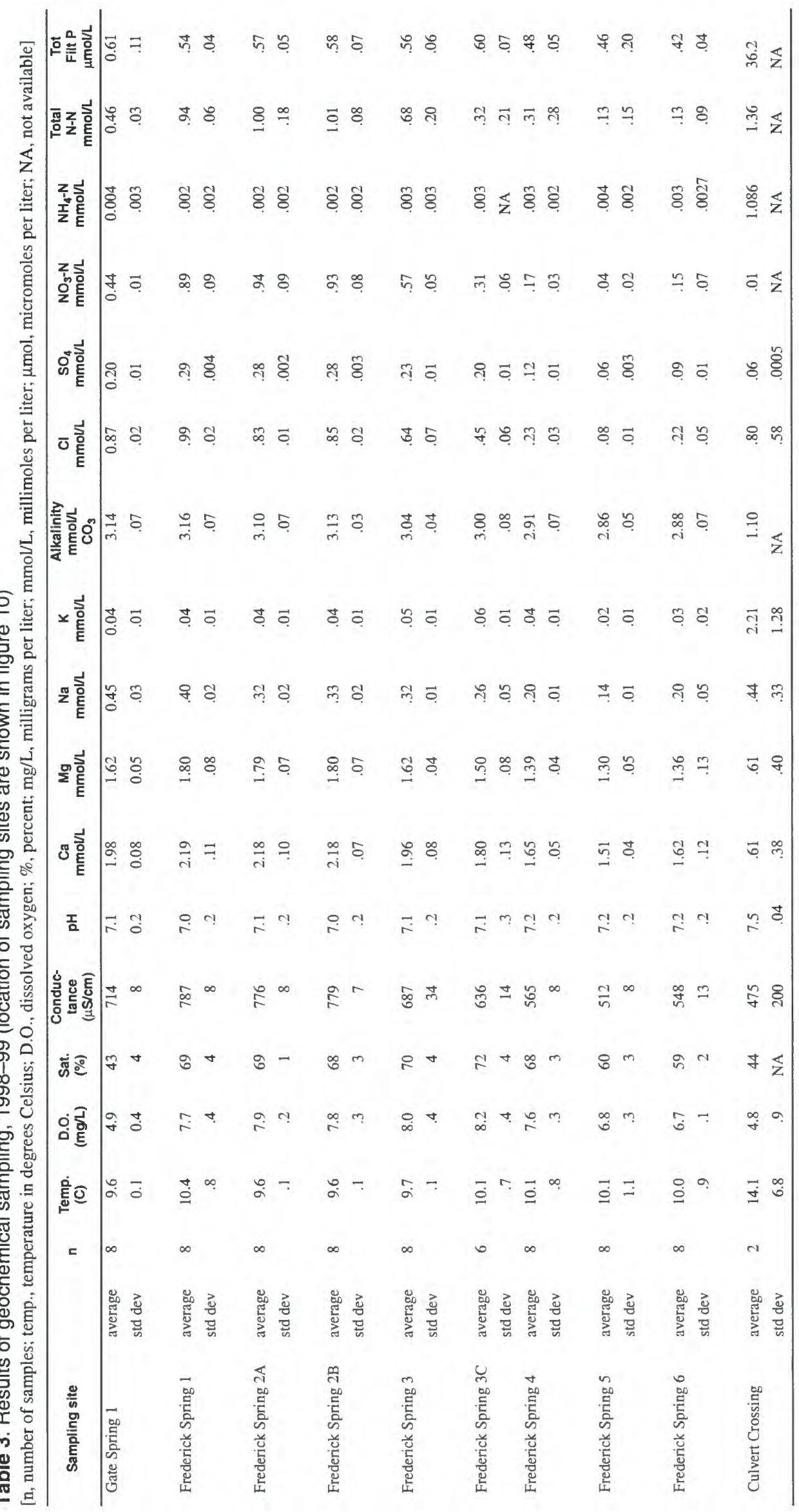




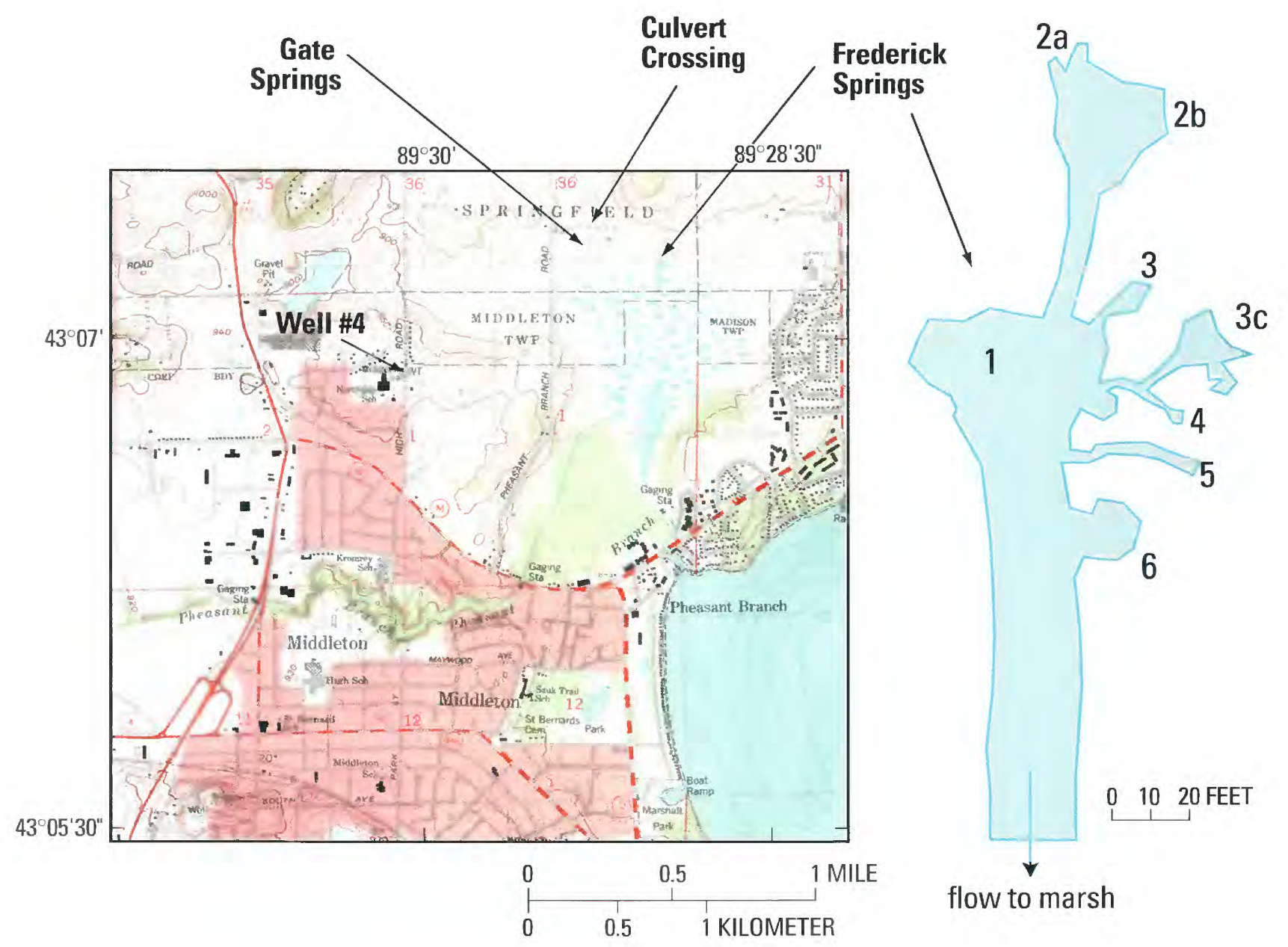

Figure 10. Location of the Springs and geochemical sampling sites included in table 3 and figures 11-19. (The Frederick Spring complex consists of eight spring vents located in an $80 \mathrm{ft}$ by $120 \mathrm{ft}$ area. The spring vents are numbered clockwise starting from the western edge.)

fig. 15) and water that was influenced by a Cambrian sandstone component in the eastern vents (Frederick Springs 5 and 6 in fig. 15). The two components identified can be used to provide additional evidence for the capture zone calculated by the stochastic particle tracking described above. When the 50 percent probability capture zone is plotted on the bedrock map for Dane County (Massie-Ferch and others, in press), the western spring vents coincide with the western portion of the capture zone that is often capped by Ordovician carbonate (fig. 16). Carbonate rocks can significantly influence ground-water carbonate chemistry because of their relatively high solubility and rapid rates of dissolution. The northeastern portion of the capture zone feeds the east vents and is characterized by an absence of Ordovician carbonate, with the uppermost bedrock consisting of Cambrian sandstones (fig. 16). The eastern spring vents also have similar chemistry to Municipal Well \#4 (figs. 11, 12, and 14) - a well that is opened only to the
Cambrian sandstone. The western area of Ordovician carbonate is larger than the northeastern area where it is missing, corresponding to the qualitative assessment that the flow from western spring vents was much larger than the flow from eastern spring vents.

The water isotope oxygen- 18 samples from the spring vents also showed a difference between the western and eastern vents (fig. 14). The western vents were characterized by lighter ${ }^{18} \mathrm{O} /{ }^{16} \mathrm{O}$ ratios (had more negative values); eastern vents had slightly heavier ratios. There are a number of mechanisms that could explain this difference including factors such as different ages of water thus different climate and associated meteoric water line during recharge, amount of arable land in the recharge area (such as Darling and Bath, 1988), or differing ratio of snowmelt to rain precipitation in recharge water (Clark and Fritz, 1997). One possibility is that the elevation of the recharge area of the western vents is higher than that of the eastern vents. Others have noted 


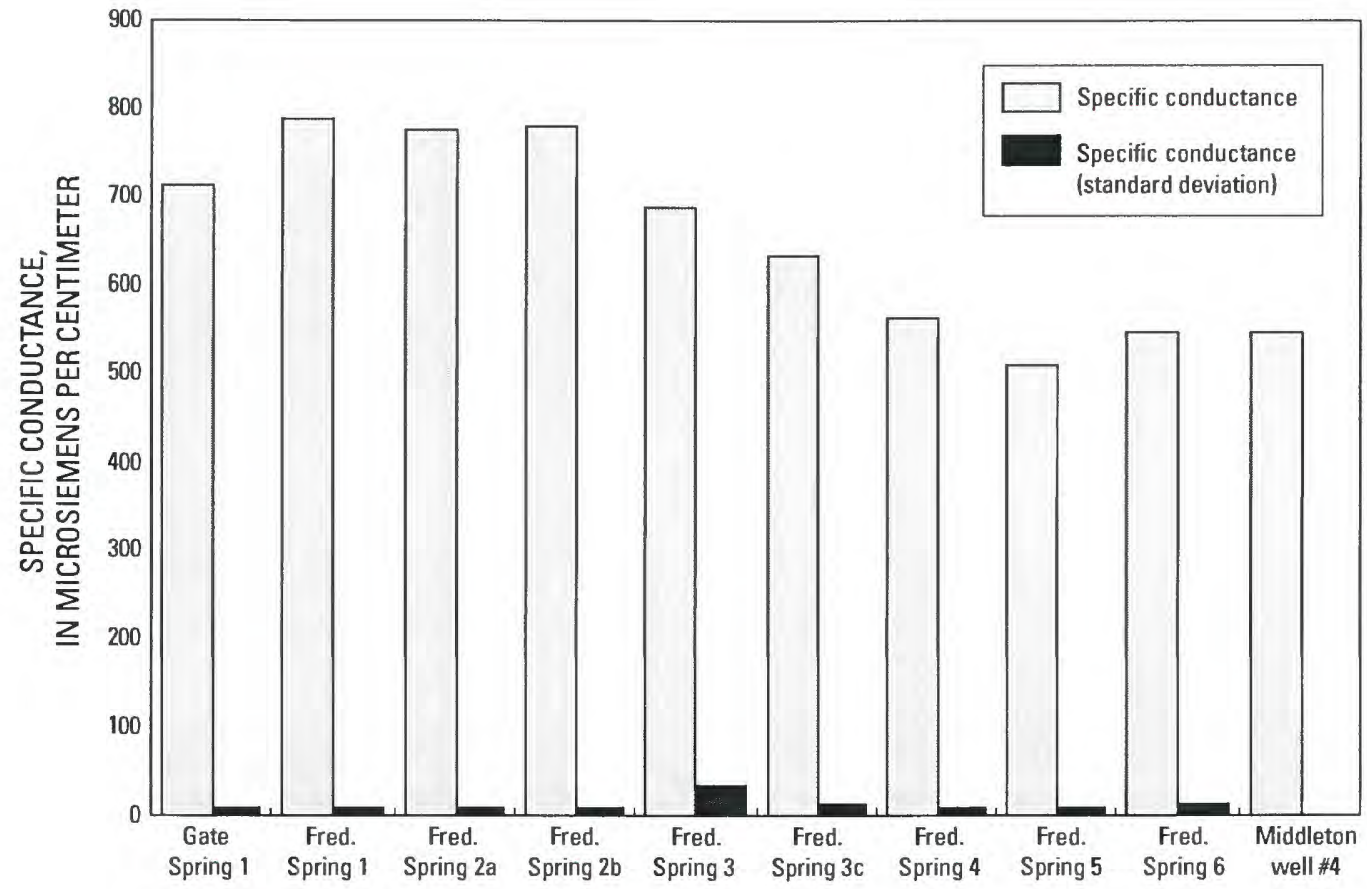

Figure 11. Average specific conductance measurements and standard deviations for 1998-99. (The largest standard deviation is observed in Frederick Spring 3, an intermediate spring between the two dominant water types; this observation suggests that the source of water to the spring may vary as transient stresses affect the system. It is notable that this is occurring in a regional discharge area.)

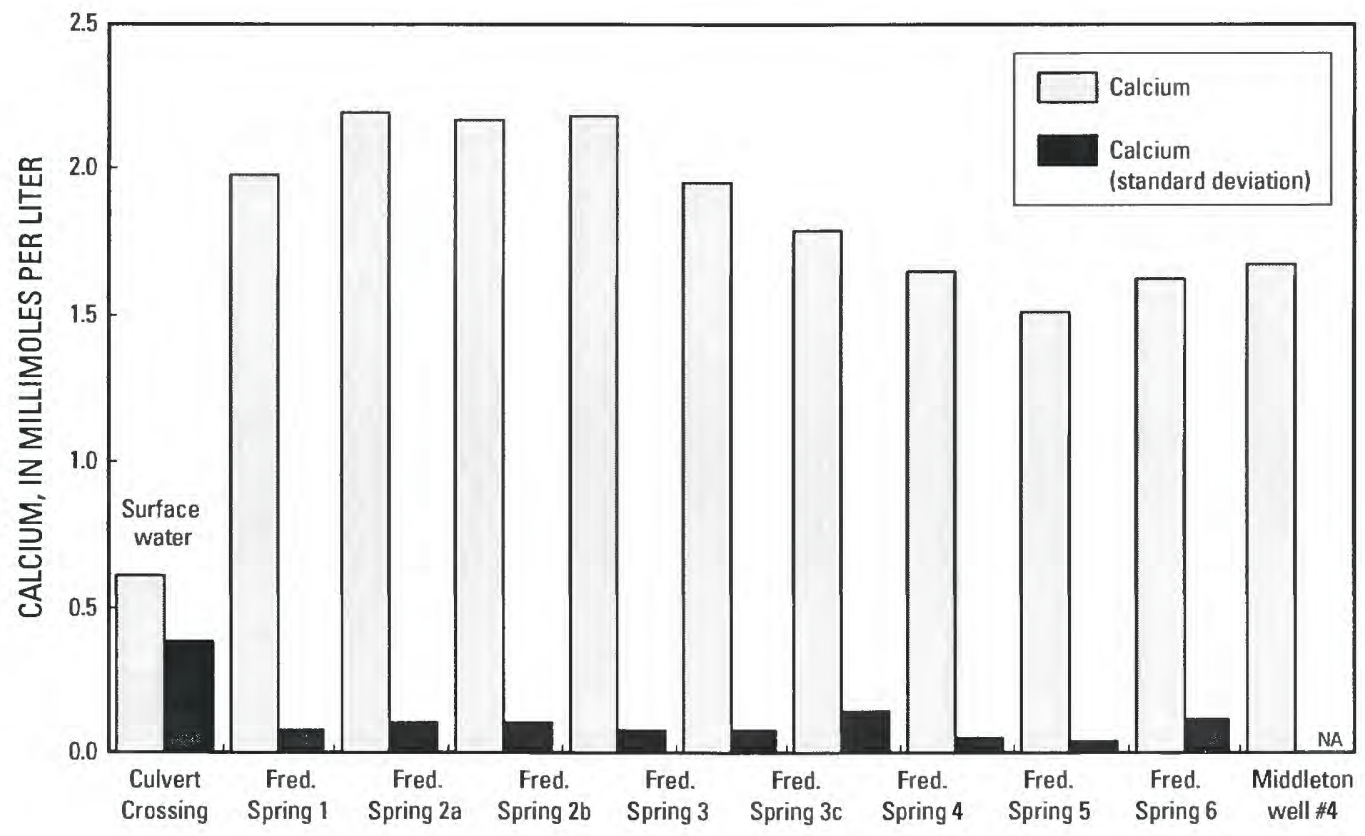

Figure 12. Average calcium concentrations and deviations for 1998-99. (The distribution of high calcium agrees well with the distribution of high specific conductance shown in figure 11.) 


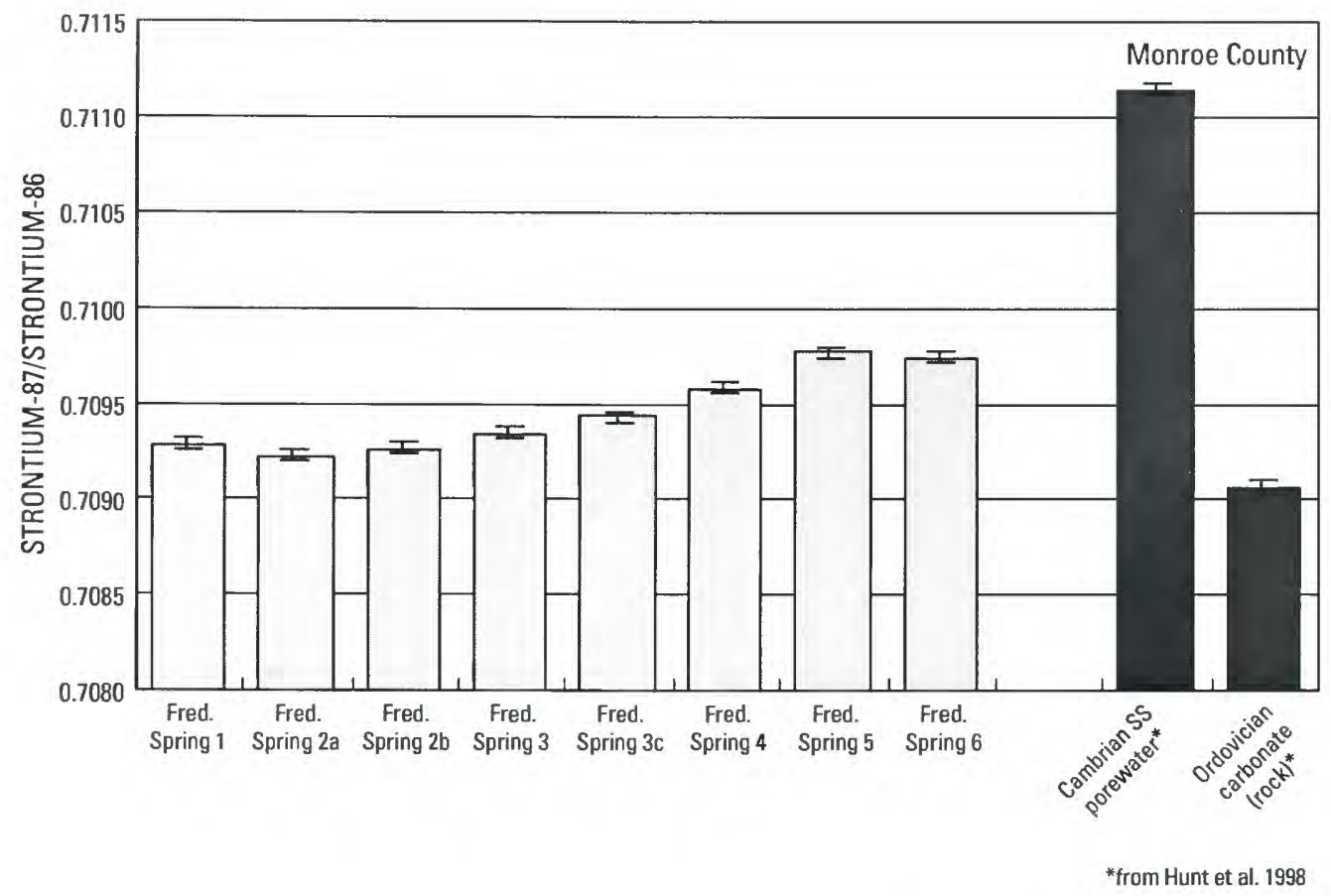

Figure 13. Average ${ }^{87} \mathrm{Sr} /{ }^{86} \mathrm{Sr}$ ratios for the March 1998 and September 1998 sampling. (Error bars reflect reported laboratory precision. Ratios obtained from a whole rock digestion of the Ordovician carbonate and porewater sampled from the Cambrian sandstone in Monroe County, Wisconsin, are also shown. Samples from the Gate Spring and the municipal well were not submitted for strontium isotope analysis.)

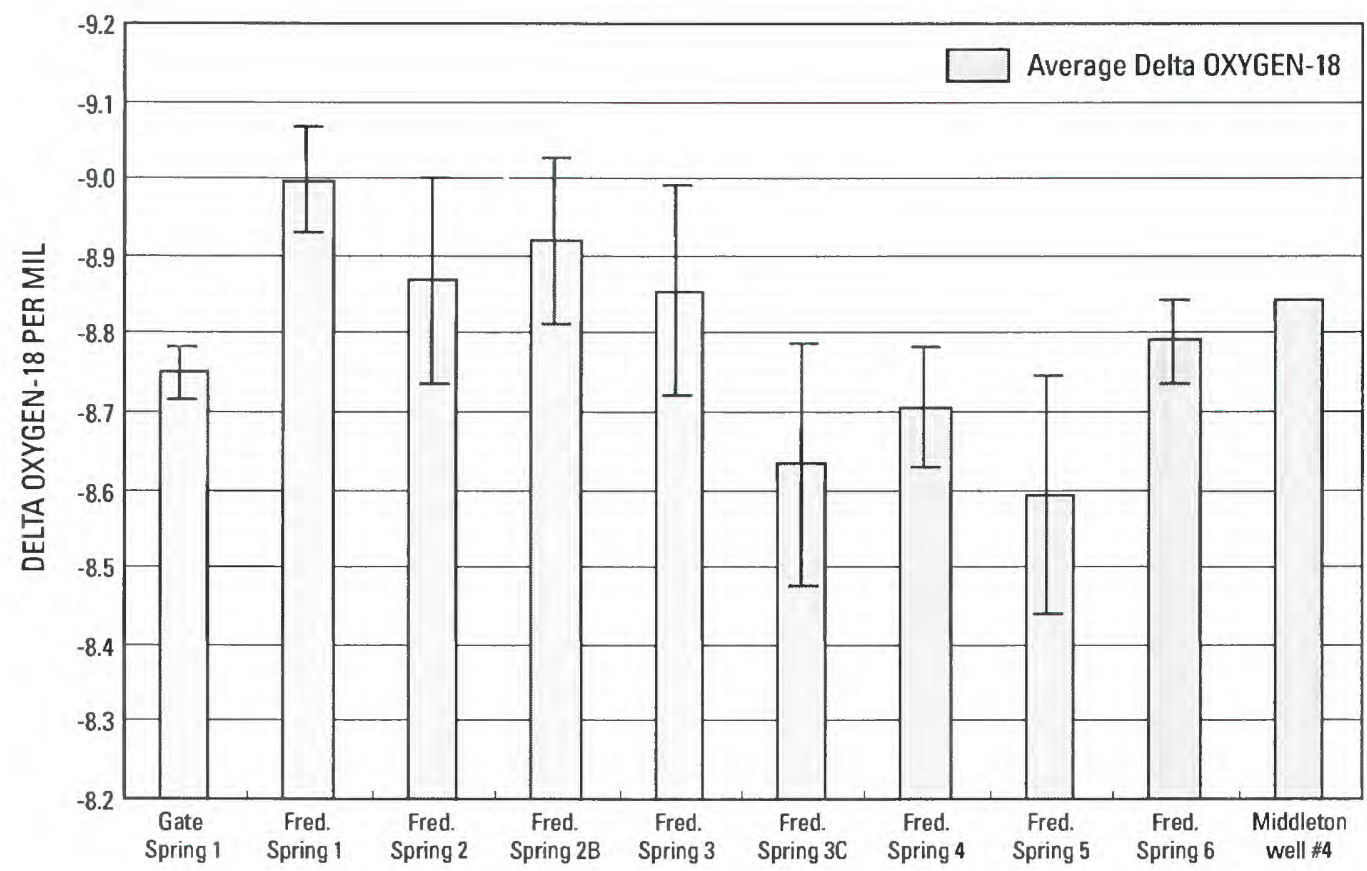

Figure 14. Average $\delta^{18} 0$ for $1998-99$. (Error bars represent 1 standard deviation for all samples measured. The municipal well was sampled only once in August 1998 therefore no error bar can be calculated. Analysis precision is plus or minus 0.1 per mil.) 


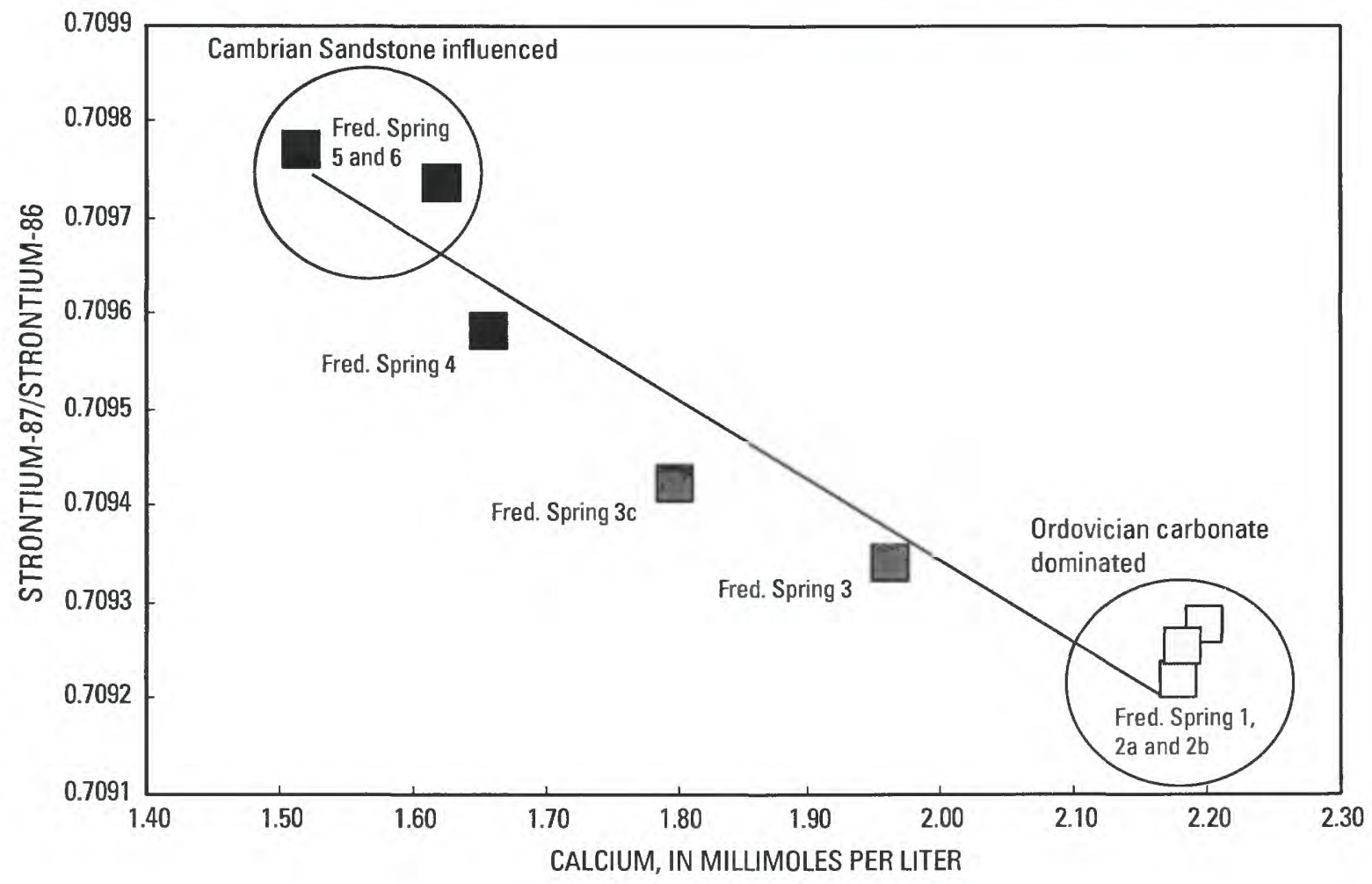

Figure 15. Average ${ }^{87} \mathrm{Sr} /{ }^{86} \mathrm{Sr}$ ratios versus average calcium concentrations for 1998-99. (The samples represent a gradation between a two-component mixing where the end members include high calcium water with a strontium isotope ratio near that measured in Ordovician carbonates and lower calcium water with a strontium isotope ratio that suggests a larger contribution from Cambrian sandstones.)

the relationship between increasing elevation and more depleted (or lighter, more negative) ${ }^{18} \mathrm{O} /{ }^{16} \mathrm{O}$ ratios; this has been observed even in areas of minor relief, with the amount of change ranging from -0.15 to -0.5 per mil for

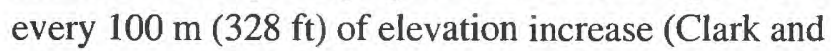
Fritz, 1997). A rough estimate of the average elevation of the recharge area was calculated using the $30 \mathrm{~m}$ (98 $\mathrm{ft}$ ) digital elevation model (DEM) for the basin and the estimated capture zones for the western and eastern vents. This calculation showed that, on average, the western portion of the capture zone was about $40 \mathrm{ft}$ higher than the eastern. While this difference is not enough to explain observed differences, the discrepancy may be due to errors in the $30 \mathrm{~m}$ DEM or inaccuracies in the exact location of the capture zone for the east and west spring vents. Alternatively, the difference in elevation may only be one factor, and other controls such as age of recharge water, land use, or slope aspect may play a role in the composition of water isotopes measured in the spring vents.
Nutrient chemistry among the spring samples also was spatially variable. Dissolved nitrate+nitrite in the western spring vents were significantly higher than eastern vents (fig. 17), likely reflecting the effects of different agricultural practices in the recharge area. Others (such as Gambrell and others, 1975) have noted that a comparison of dissolved nitrate to dissolved chloride can indicate if denitrification was occurring along the flowline from recharge area to discharge area; no evidence of denitrification was found during this study (fig. 18). Finally, as is true in most natural systems, only low concentrations of total dissolved phosphorus were observed in the ground water. Surface-water concentrations of total dissolved $\mathrm{P}$ measured in the ephemeral stream (Culvert Crossing in fig. 19), were much higher than that observed in ground water. However, there are not enough data to discern if the temporally short but high concentration surface-water input is a more important source of nutrients to the Pheasant Branch Marsh system than the longer duration, low concentration, ground-water inputs. 


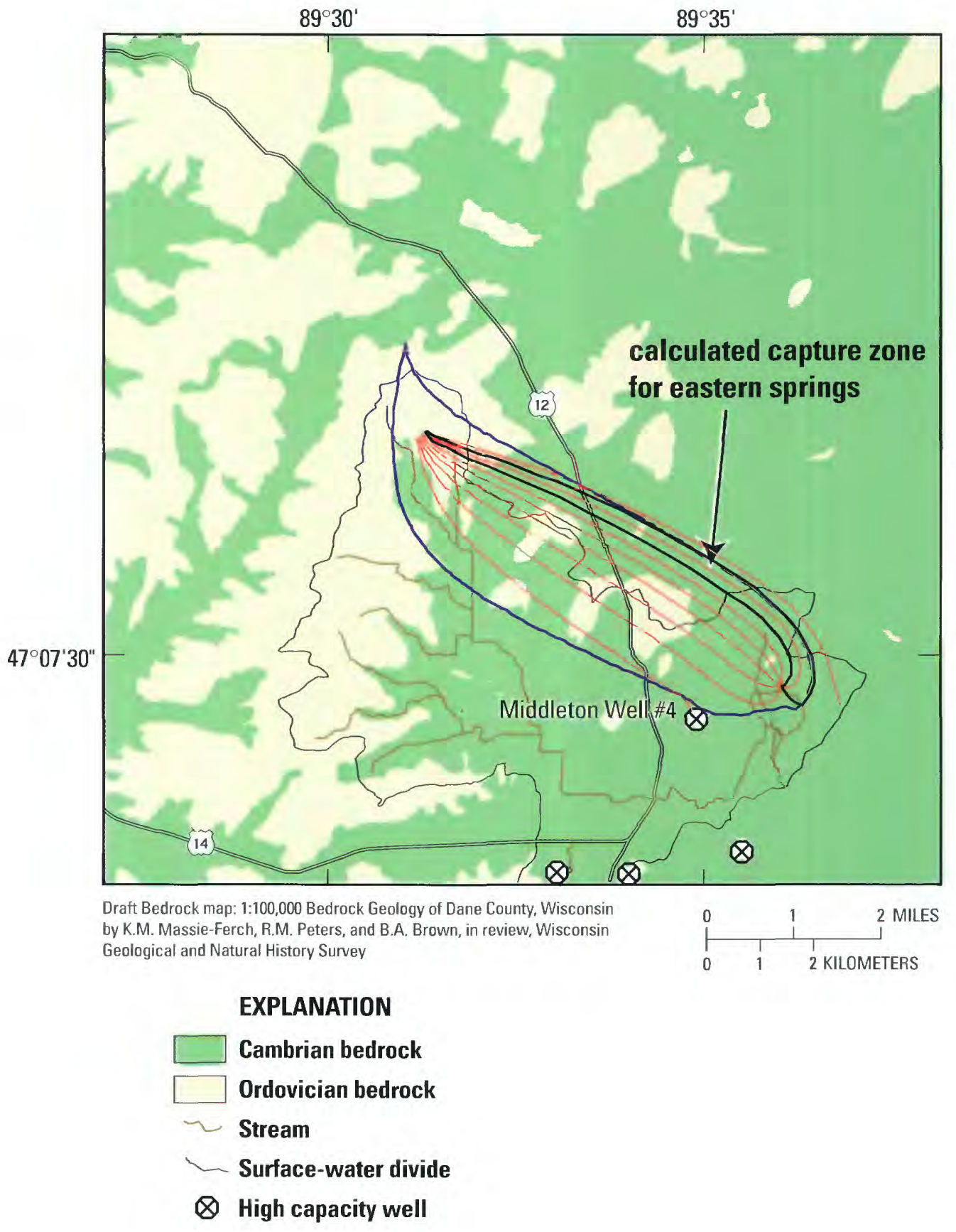

Figure 16. Results of particle tracking over the bedrock map. (The capture zone for eastern springs using the optimized model is shown within the 50 percent probability capture zone using all conditional realizations. The model results are overlain on a bedrock map of the Pheasant Branch vicinity. Areas where the Ordovician carbonate is absent (northeast areas of the capture zone) have Cambrian sandstone bedrock in the recharge areas; these areas feed eastern spring vents at Frederick Springs. The southwestern areas of the capture zones are characterized by Ordovician carbonates and are areas that feed the western spring vents.) 


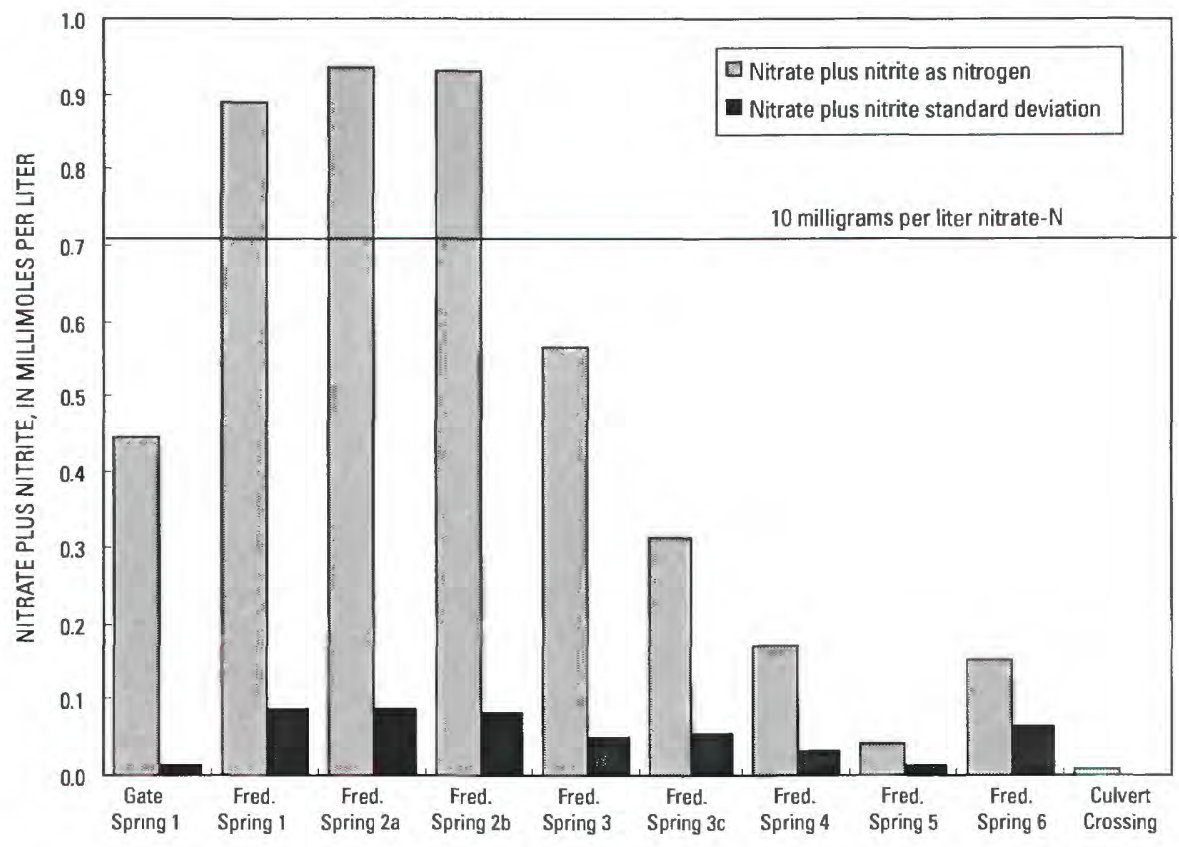

Figure 17. Average nitrate + nitrite concentrations and standard deviations for the Pheasant Branch sampling, 1998-99. (The $10 \mathrm{mg} / \mathrm{L}$ nitrate- $\mathrm{N}$ drinking water standard is shown for reference.)

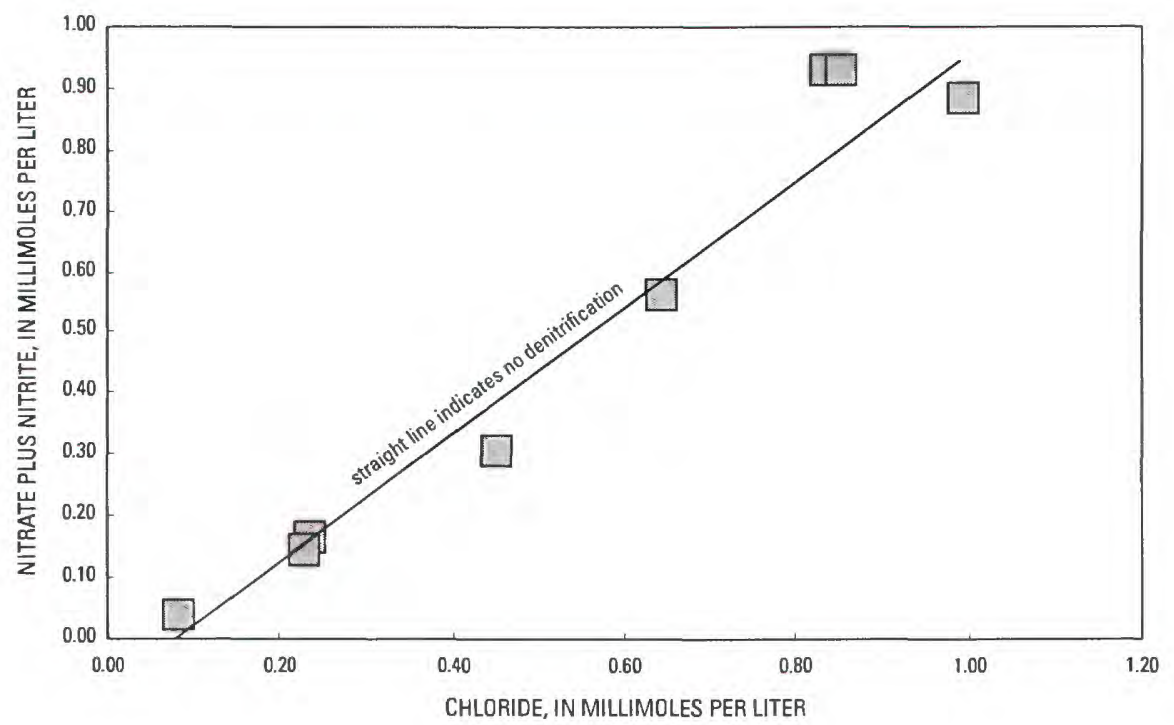

Figure 18. Average nitrate + nitrite concentrations versus average chloride concentrations for the Frederick Spring sampling, 1998-99. (The straight line indicates that denitrification (which removes nitrogen but not chloride) is not occurring.) 


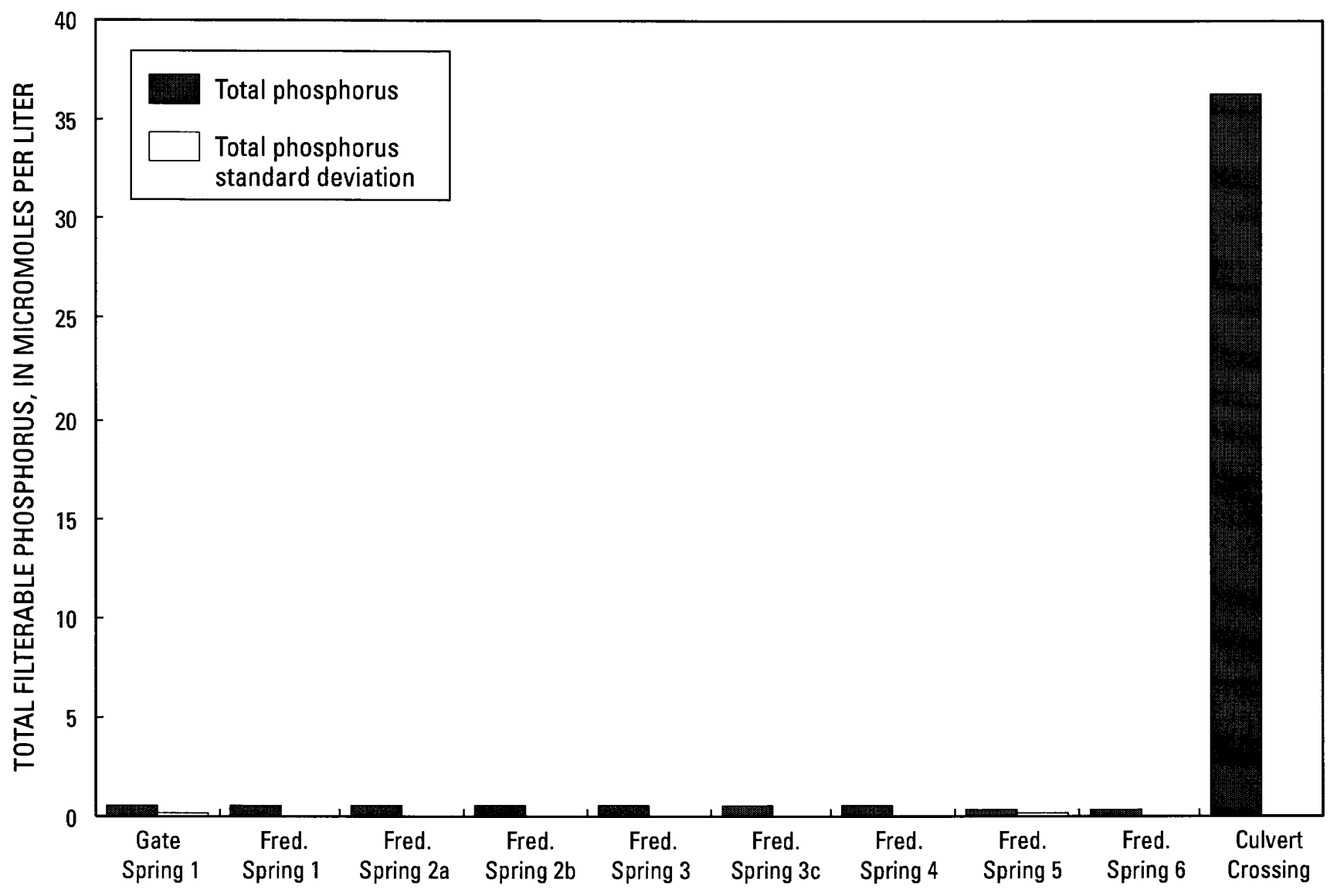

Figure 19. Average total filterable phosphorus concentrations and standard deviations for the Pheasant Branch sampling 1998-99. (As is true in the most natural systems, phosphorus is more efficiently transported in the surface water (Culvert Crossing). The Culvert Crossing surface water sampling site was only wet during the spring runoff event thus it is unclear if it is more important than the ground-water contribution on an annual scale.)

\section{SUMMARY AND CONCLUSIONS}

The Pheasant Branch watershed includes Frederick Springs, a large spring complex that flows into Pheasant Branch Marsh. As the City of Middleton and its surroundings continue to develop, the watershed is expected to undergo significant urbanization. The effects of urbanization may reduce ground-water recharge and adversely affect down-gradient hydrologic features such as Frederick Springs. The effect of stormwater runoff and wetland loss on reduced ground-water recharge is complex because the surface-water system is coupled to the underlying ground-water system. As a result, it is difficult to reliably predict the effects of urbanization on stream baseflow and spring flows a priori. Identifying the source waters for the spring, however, is the first step in ensuring its protection. Therefore, the objective of this work is to use groundwater flow modeling and geochemical investigation to identify the source of water that sustains the spring complex.

The notable findings of this work can be summarized as follows:

- The linking of the ground-water model to the surface-water model gave higher confidence in the results of both models than if either had been used independently. Values of recharge calculated with the surface-water model improved flux calibration in the ground-water model. By linking the two approaches, the entire water budget (precipitation, evapotranspiration, baseflow, stormflow and groundwater recharge) is encompassed; this helps ensure that reasonable values are used for all parameters.

- Parameter estimation sensitivity analyses on the ground-water flow model demonstrated 
that the calibration targets used in this study only supported changes in the upper bedrock aquifer (layer 2) and the lower bedrock aquifer (layer 3). Other potential parameter changes did not have significant effects on the calibration.

- Parameter estimation optimization of the ground-water flow model suggested that the horizontal hydraulic conductivity of the upper bedrock layer (layer 2 in the model) might be higher in the Pheasant Branch area than the global value that represented a best fit for the Dane County Regional Model (DCRM). The parameter estimation routine also suggests that the lower bedrock aquifer (layer 3) may have lower horizontal hydraulic conductivity than the global value used in the DCRM. The range was not exceedingly large ( 5 to $15 \mathrm{ft} / \mathrm{d}$ for layer 2, 0.7 to $10 \mathrm{ft} / \mathrm{d}$ for layer 3); insight into which values best represent the bedrock in the Pheasant Branch area was not readily available, nor within the scope of the project.

- Stochastic Monte Carlo simulations using the ground-water flow model formally addressed the uncertainty in the horizontal hydraulic conductivity identified in the parameter estimation optimization. In the Pheasant Branch model the Monte Carlo simulations sampled a range of horizontal hydraulic conductivity values spanning from 5 to $15 \mathrm{ft} / \mathrm{d}$ in layer 2 and 0.7 to $10 \mathrm{ft} / \mathrm{d}$ in layer 3 . The ranges were specified using a uniform distribution; thus, all values between the endmembers were equally likely. This approach allowed calculation of a probability distribution of the capture zone for the Springs.

- The calculated capture zone for the Springs showed that they are receiving water that was recharged from areas inside and outside of its immediate surface watershed. The capture zone encompassed the North Fork of Pheasant Branch basin, areas downstream of Highway 12 in the Pheasant Branch surface watershed, and an area outside of the Pheasant Branch watershed. This result underscored the need for linking the surface-water model of the North Fork basin to the ground-water model of the Springs, even though the surface-water systems are in different basins.
- Geochemical sampling of the Frederick Spring complex showed very large differences in chemistry between the spring vents that were located within $50 \mathrm{ft}$ of each other. The differences were stable in time, were present in both ion and isotope analyses, and showed a distinct gradation from high nitrate, high calcium, Ordovician carbonate dominated water in western spring vents to low nitrate, lower calcium, Cambrian sandstone influenced water in eastern spring vents. The difference in chemistry was explained by different bedrock geology in the recharge area as demonstrated by overlaying the 50 percent probability capture zone over a bedrock geology map for the area. This result gives additional confidence to the capture zone calculated by the ground-water flow model.

\section{REFERENCES}

Bailey, S.W., Hornbeck, J.W., and Driscoll, C.T., 1996, Calcium inputs and transport in a base-poor forest ecosystem as interpreted by $\mathrm{Sr}$ isotopes: Water Resources Research, v. 32 , no. 3, p. 707-719.

Bradbury, K.R., Swanson, S.K., Krohelski, J.T., and Fritz A.K., 1999, Hydrogeology of Dane County, Wisconsin: Wisconsin Geological and Natural History Survey Open-File Report 1999-04, 66 p.

Bullen, T.D., Krabbenhoft, D.P., and Kendall, C., 1996, Kinetic and mineralogic controls on the evolution of groundwater chemistry and ${ }^{87} \mathrm{Sr} /{ }^{86} \mathrm{Sr}$ in a sandy silicate aquifer, northern Wisconsin: Geochimica Cosmochimica Acta, v. 60, no. 10, p. 1807-1821.

Clark, I.D., and Fritz, P., 1997, Environmental Isotopes in Hydrogeology: Lewis Publishers, Boca Raton, Fla., $328 \mathrm{p}$.

Darling, W.G., and Bath, A.H., 1988, A stable isotope study of recharge process in the English Chalk: Journal of Hydrology, v. 101, p. 31-46.

D'Onofrio, A.J., 1973, Pheasant Branch Marsh environmental study_Phase 1: D'Onofrio, Kottke and Associates, Inc. Middleton, Wis., $25 \mathrm{p}$.

Driscoll, F.G., 1986, Groundwater and Wells, Second Edition: Johnson Division, St. Paul, Minn., 1,089 p.

Eastin, R., and Faure, G., 1970, Seasonal variation of the solute content and ${ }^{87} \mathrm{Sr} /{ }^{86} \mathrm{Sr}$ ratio of the Olentangy and Scioto Rivers at Columbus, Ohio: Ohio Journal of Science, v. 70, p. 170-179.

Epstein, S., and Mayeda, T., 1953, Variation of ${ }^{18} \mathrm{O}$ content of water from natural sources: Geochimica Cosmochimica Acta, v. 4, p. 213-244. 
Fisher, R., and Stueber, A.M., 1976, Strontium isotopes in selected streams within the Susquehanna River basin: Water Resources Research, v. 12, p. 1061-1068.

Gambrell, R.P., Gilliam, J.W., and Weed, S.B., 1975, Denitrification in subsoils of the North Carolina Coastal Plain as affected by soil drainage: Journal of Environmental Quality, v. 4, no. 3, p. 311-316.

Gat, J.R., 1970, Environmental isotope balance of Lake Tiberias: In Isotope Hydrology. Internal Atomic Energy Agency, Vienna, p. 109-127.

Grant, R.S., and Goddard G.L., 1980, Channel erosion and sediment transport in Pheasant Branch Basin near Middleton, Wisconsin-A preliminary report: U.S. Geological Survey Open-File Report 80-161, 19 p.

Graustein, W.C., $1989,{ }^{87} \mathrm{Sr} /{ }^{86} \mathrm{Sr}$ ratios measure the sources and flow of strontium in terrestrial ecosystems: In Stable Isotopes in Ecological Research, New York, SpringerVerlag, p. 491-512.

Hill, M.C., 1992, A computer program (MODFLOWP) for estimating parameters of a transient, three-dimensional, ground-water flow model using nonlinear regression: U.S. Geological Survey Open-File Report 91-484, 358 p. 1998, Methods and guidelines for effective model calibration: U.S. Geological Survey Water-Resources Investigation Report 98-4005, 90 p.

Holmstrom, B.K., Olson, D.L., and Ellefson, B.R., 1999, Water Resources Data Wisconsin water year 1998: U.S. Geological Survey Water-Data Report WI-98-1, p. 227-236.

Hunt, R.J., Bullen, T.D., Krabbenhoft, D.P., and Kendall, C., 1998 , Using stable isotopes of water and strontium to investigate the hydrology of a natural and a constructed wetland: Ground Water, v. 36, no. 3, p. 434-443.

Krohelski, J.T., Bradbury, K.R., Hunt, R.J., and Swanson, S.K., 2000, Numerical simulation of ground-water flow in Dane County, Wisconsin: Wisconsin Geological and Natural History Survey Bulletin 98, 44 p.

Krug, W.R., and Goddard, G.L., 1986, Effects of urbanization on streamflow, sediment loads, and channel morphology in Pheasant Branch Basin near Middleton, Wisconsin: U.S. Geological Survey Water-Resources Investigations Report 85-4068, 82 p.

Lathrop, R.C., and Johnson, C.D., 1979, Dane County Water Quality Plan: Appendix B, Water Quality Conditions, $359 \mathrm{p}$.

Leavesley, G.H., Lichty, R.W., Troutman, B.M., and Saindon, L.G., 1983, Precipitation-runoff modeling systemuser's manual: U.S. Geological Survey Water Resources Investigations Report 83-4238, 207 p.
Maher, L.J., 1999, The early history of the Pheasant Branch watershed: Appendix 3, unpublished report from the North Fork Pheasant Branch Watershed Committee, http://www.geology.wisc.edu/ maher/pheasant_branch.html.

Massie-Ferch, K.M., Peters, R.M., and Brown, B.A., in press, Bedrock Geology of Dane County, Wisconsin: Wisconsin Geological and Natural History Survey, scale 1:100,000.

McDonald, M.G., and Harbaugh, A.W., 1988, A Modular Three-Dimensional Finite-Difference Ground-Water Flow Model: U.S. Geological Survey Techniques of Water-Resources Investigations Report, bk. 6, chap. A1, $576 \mathrm{p}$.

North Fork Pheasant Branch Watershed Committee, 1999, unpublished "A Report From The North Fork Pheasant Branch Watershed Committee", http://www.geology.wisc.edu/ maher/pheasant_branch.html.

Poeter, E.P., and Hill, M.C., 1997, Inverse models-A necessary next step in ground-water modeling: Ground Water, v. 35 , no. 2 , p. $250-260$.

Poeter, E.P., and Hill, M.C., 1998, Documentation of UCODE, a computer code for universal inverse modeling: U.S. Geological Survey Water-Resources Investigation Report 98-4080, $116 \mathrm{p}$.

Prudic, D.E., 1989, Documentation of a computer program to simulate stream-aquifer relations using a modular, finite difference ground-water flow model: U.S. Geological Survey Open-File Report 88-729, 113 p.

Rumbaugh, J.O., and Rumbaugh, D.B., 1996, Guide to using Groundwater Vistas: Advanced model design \& analysis, Environmental Simulations, Inc., 180 p.

Ruskauff, G.J., Rumbaugh, J.O., and Rumbaugh, D.B., 1998, Stochastic MODFLOW for Monte Carlo Simulation: Environmental Simulations Incorporated, Herndon, Va., $58 \mathrm{p}$.

Selbig, W.R., 1996, Pheasant Branch Marsh-Interpretive study for Spring of 1996: Unpublished report for Institute of Environmental Studies 361, University of WisconsinMadison, $36 \mathrm{p}$.

Stumm, W., and Morgan, J.J., 1981, Aquatic Chemistry: John Wiley and Sons, New York, 780 p.

Swanson, S.K., 1996, A comparison of two methods for estimating groundwater recharge in Dane County, Wisconsin: M.S. Thesis, Department of Geology and Geophysics, University of Wisconsin-Madison, $123 \mathrm{p}$.

Young, H.L., 1992, Hydrogeology of the Cambrian-Ordovician Aquifer System in the Northern Midwest, United States: U.S. Geological Survey Professional Paper 1405-B, $99 \mathrm{p}$. 


8 Printed on recycled paper 



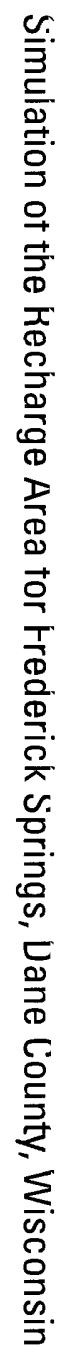

$\sum_{3}$
$\bar{J}$
0
0
$\stackrel{N}{N}$ 